\title{
Structural Insight into Methyl-Coenzyme M Reductase Chemistry using Coenzyme B Analogues,,$+ \neq$
}

\author{
Peder E. Cedervall§,\#, Mishtu Dey $\|, \#, \perp$, Arwen R. Pearson $§, \perp$, Stephen W. Ragsdale $\|$, and \\ Carrie M. Wilmot ${ }^{\star}, \|, \S$ \\ $\S$ Department of Biochemistry, Molecular Biology and Biophysics, University of Minnesota, \\ Minneapolis, Minnesota 55455 \\ I| Department of Biological Chemistry, University of Michigan, Ann Arbor, Michigan 48109
}

\section{Abstract}

Methyl-coenzyme M reductase (MCR) catalyzes the final and rate-limiting step in methane biogenesis; the reduction of methyl-coenzyme $\mathrm{M}$ (methyl-SCoM) by coenzyme $\mathrm{B}$ (CoBSH) to methane and a heterodisulfide (CoBS-SCoM). Crystallographic studies show that the active site is deeply buried within the enzyme, and contains a highly reduced nickel-tetrapyrrole, coenzyme $\mathrm{F}_{430}$. Methyl-SCoM must enter the active site prior to $\mathrm{CoBSH}$, as species derived from analogues of methyl-SCoM are always observed bound to the $\mathrm{F}_{430}$ nickel in the deepest part of the $30 \AA$ long substrate channel that leads from the protein surface to the active site. The seven-carbon mercaptoalkanoyl chain of CoBSH binds within a $16 \AA$ predominantly hydrophobic part of the channel close to $\mathrm{F}_{430}$, with the CoBSH thiolate lying closest to the nickel at a distance of $8.8 \AA$. It has previously been suggested that binding of CoBSH initiates catalysis by inducing a conformational change that moves methyl-SCoM closer to the nickel promoting cleavage of the C$\mathrm{S}$ bond of methyl-SCoM. In order to better understand the structural role of CoBSH early in the MCR mechanism, we have determined crystal structures of MCR in complex with four different CoBSH analogues; pentanoyl-, hexanoyl-, octanoyl- and nonanoyl- derivatives of CoBSH $\left(\mathrm{CoB}_{5} \mathrm{SH}, \mathrm{CoB}_{6} \mathrm{SH}, \mathrm{CoB}_{8} \mathrm{SH}\right.$ and $\mathrm{CoB}_{9} \mathrm{SH}$ respectively). The data presented here reveal that the shorter $\mathrm{CoB}_{5} \mathrm{SH}$ mercaptoalkanoyl chain overlays with that of $\mathrm{CoBSH}$, but terminates two units short of the CoBSH thiolate position. In contrast, the mercaptoalkanoyl chain of $\mathrm{CoB}_{6} \mathrm{SH}$ adopts a different conformation, such that its thiolate is coincident with the position of the CoBSH thiolate.

\footnotetext{
${ }^{\dagger}$ This work was supported by a Department of Energy grant DE-FG02-08ER15931 to S.W.R and supplement to C.M.W. and a Minnesota Partnership for Biotechnology and Medical Genomics grant SPAP-05-0013-P-FY06.

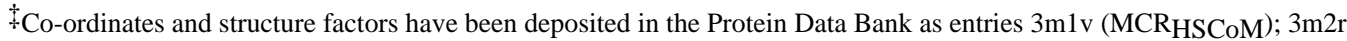
(MCR $\left.{ }_{\mathrm{CoB} 5 \mathrm{SH}}\right) ; 3 \mathrm{~m} 2 \mathrm{u}\left(\mathrm{MCR}_{\mathrm{CoB}} 6 \mathrm{SH}\right) ; 3 \mathrm{~m} 2 \mathrm{v}$ (MCR $\left.\mathrm{CoB} 8 \mathrm{SH}\right) ; 3 \mathrm{~m} 30$ (MCR $\left.\mathrm{MoB}_{\mathrm{SHH}}\right)$.

*Address correspondence to: Carrie M. Wilmot, Tel: (612) 624-2406, wilmo004@umn.edu.

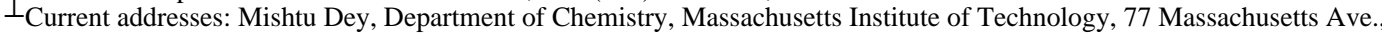
Cambridge, Massachusetts 02139; Arwen Pearson, Astbury Centre for Structural Molecular Biology, Institute for Molecular and Cellular Biology, Astbury Building. Leeds, LS2 9JT, U.K.

\#These authors contributed equally to this work.

Supporting Informational material is available free of charge via the Internet at http://pubs.acs.org and contains the following: MATERIAL AND METHODS for single crystal UV-visible microspectrophotometry, X-ray photoreduction experiment and X-ray crystallography of the MCR-heterodisulfide product complex (MCR CoBSH + methyl-SCoM); RESULTS AND DISCUSSION for redox changes and $\mathrm{MCR}_{\mathrm{CoBSH}}+$ methyl-SCoM crystal structure; Table S1, X-ray Data Collection, Processing and Refinement Statistics for MCRCoBSH + methyl-SCoM; Figure S1, use of Fo-Fc electron density in modelling MCRCoB8SH; Figure S2, illustration of electron density quality of $\mathrm{MCR}_{\mathrm{CoB} 5 \mathrm{SH}}$; Figure S3, solution and single crystal UV-visible spectra; Figure S4, modeling of $\mathrm{CoB}_{6} \mathrm{SH}$ and $\mathrm{CoBSH}$ into the electron density of MCR $\mathrm{CoB}_{\mathrm{SSH}}$; Figure S5, partially occupied HSCoM in MCR $\mathrm{CoB}_{6 \mathrm{SH}}$; Figure S6, the active site and substrate channel of MCRCoBSH + methyl-SCoM; Figure S7, alternative conformation of Vala482 in

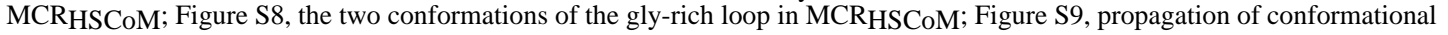
changes in MCR $\mathrm{HSCoM}$; Figure S10, the two conformations of $\mathrm{CoB} 9 \mathrm{SH}$ in $\mathrm{MCR}_{\mathrm{CoB}}$ 9SH; Figure S11, EPR spectra of $\mathrm{MCR}_{\mathrm{red}} 1$ sample; Scheme S1, scheme of the characterized forms of MCR.
} 
This is consistent with the observation that $\mathrm{CoB}_{6} \mathrm{SH}$ is a slow substrate. A labile water in the substrate channel was found to be a sensitive indicator for the presence of CoBSH and HSCoM. The longer $\mathrm{CoB}_{8} \mathrm{SH}$ and $\mathrm{CoB}_{9} \mathrm{SH}$ analogues can be accommodated in the active site through exclusion of this water. These analogues react with $\mathrm{Ni}(\mathrm{III})$-methyl; a proposed MCR catalytic intermediate of methanogenesis. The $\mathrm{CoB}_{8} \mathrm{SH}$ thiolate is $2.6 \AA$ closer to the nickel than that of $\mathrm{CoBSH}$, but the additional carbon of $\mathrm{CoB}_{9} \mathrm{SH}$ only decreases the nickel thiolate distance a further $0.3 \AA$ A Although the analogues did not induce any structural changes in the substrate channel, the thiolates appeared to preferentially bind at two distinct positions in the channel; one being the previously observed CoBSH thiolate position, and the other being at a hydrophobic annulus of residues that lines the channel proximal to the nickel.

\section{INTRODUCTION}

Methanogenic archaea are organisms that under strict anaerobic conditions derive energy by reducing compounds such as carbon dioxide, methylamine, acetate and methanol, to methane $(1,2)$. The global production of methane by these organisms is estimated at one billion tons annually. Microbially produced methane is not only a potential source of renewable energy but also a potent greenhouse gas, and as such study of this process has environmental ramifications. In these microorganisms, methyl-coenzyme $\mathrm{M}$ reductase $(\mathrm{MCR})^{1}$ is the enzyme that catalyzes the final step in methanogenesis, in which the substrates methyl-coenzyme M (methyl-SCoM, 2-(methylthio)ethanesulfonate) and coenzyme B (CoBSH, $N$-7-mercaptoheptanoylthreonine phosphate) are converted to methane and a heterodisulfide (CoBS-SCoM) (Scheme 1) (3).

MCR is a $300 \mathrm{kDa}$ protein with six subunits arranged in a $\alpha_{2} \beta_{2} \gamma_{2}$ oligomer (4). The known crystal structures show that MCR has two active sites approximately $50 \AA$ apart that are deeply buried within the enzyme (5). The active site pocket is comprised of residues from subunits $\alpha, \alpha^{\prime}, \beta$ and $\gamma$, with a $30 \AA$ long substrate channel leading to the enzyme surface (Figure 1). At the heart of the active site pocket is coenzyme $\mathrm{F}_{430}$, which is a highly reduced nickel-containing tetrapyrrole (6-8). Currently sixteen distinct enzymatic and complexed states of MCR have been spectroscopically characterized (Supporting Information, Scheme S1) (9-31). In the resting active state of the enzyme, denoted $\mathrm{MCR}_{\mathrm{red} 1}$, the redox-active nickel of $\mathrm{F}_{430}$ is present in the $\mathrm{Ni}(\mathrm{I})$ state $(9,16,32)$. MCR is extremely oxygen sensitive and upon oxygen exposure the enzyme enters an inactive $\mathrm{Ni}$ (II) state, denoted $\mathrm{MCR}_{\text {red1-silent }}$ (6). In this state it cannot be converted back to the active $\mathrm{Ni}(\mathrm{I})$ form by any known reducing agent making this a challenging system to study. Additional complications involve the tight association of coenzymes to purified MCR that are not easily displaced as demonstrated by $\mathrm{X}$-ray crystallographic and kinetic studies $(5,33-35)$.

Despite the fact that MCR has been studied for decades, no true catalytic intermediate has been observed, and the actual mechanism remains elusive. Currently three general mechanistic schemes for the enzymatic reaction have been proposed, each of which posit different chemistry to initiate catalysis. Mechanism I involves Ni(I) acting as a nucleophile in an $\mathrm{S}_{\mathrm{N}}$ 2-type reaction that generates $\mathrm{Ni}$ (III)-methyl as an intermediate (Scheme 2A) (3538). Mechanism II starts with methyl-SCoM undergoing homolytic cleavage at the $\mathrm{Ni}(\mathrm{I})$ to generate a methyl radical and a Ni(II)-SCoM species (Scheme 2B) (39-41). A more recently proposed mechanism III suggests protonation of coenzyme $\mathrm{F}_{430}$ promotes reductive cleavage of the methyl-SCoM thioether bond (42).

\footnotetext{
${ }^{1}$ Abbreviations: MCR, Methyl-coenzyme M reductase; methyl-SCoM, methyl-coenzyme M; CoBSH, coenzyme B; HSCoM, coenzyme M; CoBS-SCoM, heterodisulfide of coenzyme B and coenzyme M; APS, Advanced Photon Source; ASU, asymmetric unit; BPS, bromopropanesulfonate.
} 
Due to the stringent requirement to exclude $\mathrm{O}_{2}$, the available MCR crystal structures are all in the inactive $\mathrm{Ni}$ (II) state. All but one contain CoBSH and HSCoM (demethylated methyl$\mathrm{SCoM}$, an inhibitor and substrate analogue) in the active site (PDB codes 1hbn, 1hbo, 1hbu, 1e6y, 1e6v) $(5,33,34)$. Another crystal structure has bound heterodisulfide product, CoBSSCoM (MCR silent PDB code $1 \mathrm{hbm}$, Scheme 1 and Supporting Information, Scheme S1) (5, 33). All these structures reveal that both substrates access the active site through the same channel (Figure 1). The binding site of HSCoM (and presumably methyl-SCoM) is more deeply buried within the enzyme, and so it must enter prior to CoBSH for productive chemistry to occur. As binding of CoBSH in the absence of co-substrate would be inhibitory, it was suggested that a conformational change upon methyl-SCoM binding might lower the $K_{\mathrm{d}}$ for CoBSH, and thus promote an ordered mechanism. Furthermore it has been suggested that CoBSH binding induces a conformational change that brings the methylSCoM substrate into closer proximity to the nickel, and this promotes $\mathrm{C}-\mathrm{S}$ bond cleavage. To investigate the proposed structural role of CoBSH in initiating catalysis, we have solved the X-ray crystal structures of MCR in complex with four different CoBSH analogues. CoBSH has a heptanoyl moiety linked to the thiol group, and the analogues are pentanoyl-, hexanoyl-, octanoyl- or nonanoyl-containing derivatives of $\mathrm{CoBSH}\left(\mathrm{CoB}_{5} \mathrm{SH}, \mathrm{CoB}_{6} \mathrm{SH}\right.$, $\mathrm{CoB}_{8} \mathrm{SH}$ and $\mathrm{CoB}_{9} \mathrm{SH}$ respectively; Figure 2) (3, 35, 43-47). In addition, we present a structure in which the substrate channel predominantly lacks either CoBSH or heterodisulfide product.

\section{MATERIALS AND METHODS}

\section{Materials}

The organism Methanothemobacter marburgensis (catalog OCM82) was obtained from the Oregon Collection of Methanogens (Portland, OR). All buffers and media reagents were obtained from Sigma-Aldrich (St. Louis, MO). The gases $\mathrm{N}_{2}(99.98 \%), \mathrm{H}_{2} / \mathrm{CO}_{2}(80 \% / 20 \%)$, and ultra high purity $\mathrm{H}_{2}(99.999 \%)$ were obtained from Cryogenic Gases (Grand Rapids, MI). Ti(III) citrate solutions were prepared from a stock solution of $246 \mathrm{mM}$ Ti(III) citrate, which was synthesized by adding sodium citrate to Ti(III) trichloride ( $30 \mathrm{wt} \%$ solution in 2 $\mathrm{N}$ hydrochloric acid) (Acros Organics, Morris Plains, NJ) under anaerobic conditions and adjusting $\mathrm{pH}$ to 7.0 with sodium bicarbonate (48). The concentration of $\mathrm{Ti}(\mathrm{III})$ citrate was determined by titrating against a solution of methyl viologen.

\section{Synthesis of methyl-SCoM, $\mathrm{CoB}_{5} \mathrm{SH}, \mathrm{CoB}_{6} \mathrm{SH}, \mathrm{CoBSH}, \mathrm{CoB}_{8} \mathrm{SH}$, and $\mathrm{CoB}_{9} \mathrm{SH}$}

Methyl-SCoM was prepared from HSCoM and methyl iodide (49). The homodisulfides, $\mathrm{CoB}_{5} \mathrm{~S}-\mathrm{SCoB}_{5}, \mathrm{CoB}_{6} \mathrm{~S}-\mathrm{SCoB}_{6}, \mathrm{CoBS}-\mathrm{SCoB}, \mathrm{CoB}_{8} \mathrm{~S}-\mathrm{SCoB}_{8}, \mathrm{CoB}_{9} \mathrm{~S}-\mathrm{SCoB}_{9}$ were prepared as described from 5-bromovaleric acid, 6-bromohexanoic acid (Sigma-Aldrich, St. Louis, MO), 7-bromoheptanoic acid (Karl Industries, Aurora, OH), 8-bromooctanoic acid, and 9bromononanoic acid (Matrix Scientific, Columbia, SC), respectively $(43,46)$. The free thiol forms of $\mathrm{CoB}_{5} \mathrm{SH}, \mathrm{CoB}_{6} \mathrm{SH}, \mathrm{CoBSH}_{,} \mathrm{CoB}_{8} \mathrm{SH}$, and $\mathrm{CoB}_{9} \mathrm{SH}$ were generated by the reduction of the homodisulfides as previously described (45). The purity of the CoBSH analogues was determined by ${ }^{1} \mathrm{H}$ NMR spectroscopy. All compounds synthesized were stored in a Vacuum Atmospheres chamber maintained at an oxygen level below $1 \mathrm{ppm}$, as monitored continually with an oxygen analyzer (model 317, Teledyne Analytical Instruments, City of Industry, CA) until use.

\section{M. marburgensis Growth and $\mathbf{M C R}_{\text {red1 }}$ Purification}

Buffer preparations and all manipulations were performed under strict anaerobic conditions in a Vacuum Atmospheres chamber maintained at an oxygen level below $1 \mathrm{ppm}$, as monitored continually with an oxygen analyzer (model 317, Teledyne Analytical Instruments, City of Industry, CA). $\mathrm{MCR}_{\text {red1 }}$ was isolated from M. marburgensis cultured on 
$\mathrm{H}_{2} / \mathrm{CO}_{2}(80 \% / 20 \%)$ at $65{ }^{\circ} \mathrm{C}$ in a $14-\mathrm{L}$ fermentor (New Brunswick Scientific Co., Inc. New Brunswick, NJ). Culture media were prepared as previously described $(20,24)$. $\mathrm{MCR}_{\text {red1 }}$ was generated in vivo and purified as described previously (20). The purification procedure routinely generates $65-75 \% \mathrm{MCR}_{\text {red1 }}$ as determined by UV-visible and EPR spectroscopy.

\section{Spectroscopy of MCR}

$\mathrm{UV}$-visible spectra of the $\mathrm{Ni}(\mathrm{I})$-containing $\mathrm{MCR}_{\mathrm{red} 1}$ were recorded in the anaerobic chamber using a spectrophotometer (Model USB4000-UV-VIS, Ocean Optics, Dunedin, FL). EPR spectra were recorded on a Bruker EMX spectrometer (Bruker Biospin Corp., Billerica, MA), equipped with an Oxford ITC4 temperature controller, a Hewlett-Packard Model 5340 automatic frequency counter and Bruker gaussmeter. The EPR spectroscopic parameters included: temperature, $70 \mathrm{~K}$; microwave power, $10 \mathrm{~mW}$; microwave frequency, $9.43 \mathrm{GHz}$; receiver gain, $2 \times 10^{4}$; modulation amplitude, $10.0 \mathrm{G}$; modulation frequency, $100 \mathrm{kHz}$. Double integrations of the EPR spectra were performed and referenced to a $1 \mathrm{mM}$ copper perchlorate standard. The NMR data were acquired at $298 \mathrm{~K}$ on a Bruker Avance DRX 500 $\mathrm{MHz}$ instrument equipped with a TXI cryoprobe.

\section{Preparation of $\mathbf{M C R}_{\text {red1 } 1}$ for Crystallization}

All crystallization experiments were performed in the anaerobic chamber in which MCR was purified unless otherwise noted. MCR $_{\text {red } 1}$ was prepared in $50 \mathrm{mM}$ Tris, $\mathrm{pH} 7.6$ and excess HSCoM was removed by buffer exchange using an Amicon Ultra centrifuge filter with a $50 \mathrm{kDa}$ cut-off membrane (Millipore). Typically, $2-3 \mathrm{ml}$ of $\mathrm{MCR}_{\text {red1 }}$ was exchanged with $10-15 \mathrm{ml}$ of $50 \mathrm{mM}$ Tris, $\mathrm{pH}$ 7.6. The enzyme was concentrated to 500-600 $\mu \mathrm{l}$, and this process was repeated three times. The fraction of $\mathrm{MCR}_{\text {red1 }}$ in the purified MCR sample was calculated from the UV-visible spectrum using extinction coefficients of 27.0 $\mathrm{mM}^{-1} \mathrm{~cm}^{-1}$ at $385 \mathrm{~nm}$ for $\mathrm{Ni}(\mathrm{I})-\mathrm{MCR}_{\text {red1 }}$, and $9.15 \mathrm{mM}^{-1} \mathrm{~cm}^{-1}$ at $420 \mathrm{~nm}$ for $\mathrm{Ni}(\mathrm{II})-$ $\mathrm{MCR}_{\text {red1-silent }}(20)$. The amount of $\mathrm{MCR}_{\text {red1 }}$ in samples used for crystallization was determined to be $\sim 80 \%$ and the concentration of total enzyme used was in the range of about $120-150 \mu \mathrm{M}(\sim 32-40 \mathrm{mg} / \mathrm{ml})$. All crystallization experiments were performed anaerobically by incubating $2.0 \mu \mathrm{l}$ of enzyme solution in $50 \mathrm{mM}$ Tris, $\mathrm{pH} 7.5$ and $2.0 \mu \mathrm{l}$ of reservoir solution (100 mM Hepes-Na, $\mathrm{pH} 7.3 / 7.5 / 8.0 ; 150 \mathrm{mM}$ magnesium acetate $\left(\mathrm{Mg}\left(\mathrm{CH}_{3} \mathrm{COO}\right)_{2}\right)$, and 20/22\% (w/v) PEG 400) in a sitting drop over $1 \mathrm{ml}$ reservoir solution at $9^{\circ} \mathrm{C}$. Triangular and rectangular prismatic crystals with a bright yellowish-green color confirmed the presence of nickel coenzyme $F_{430}$. The crystals grew to a size of approximately 100-200 $\mu \mathrm{m}$ in 4-5 days. CoBSH-depleted crystals were obtained by incubating $2 \mu \mathrm{l}$ of a reaction mixture containing $139 \mu \mathrm{M} \mathrm{MCR}_{\text {red1 }}$ and $13 \mathrm{mM} \mathrm{HSCoM}$ with $2 \mu \mathrm{l}$ of reservoir solution (100 mM Hepes-Na pH 7.5, $150 \mathrm{mM}$ magnesium acetate $\left(\mathrm{Mg}\left(\mathrm{CH}_{3} \mathrm{COO}\right)_{2}\right), 22 \%$ PEG 400). Crystals of MCR complexed with the CoBSH analogues were grown by co-crystallization. The $\mathrm{CoB}_{5} \mathrm{SH}$ co-crystals were obtained by incubating $2 \mu \mathrm{l}$ enzyme solution containing 124 $\mu \mathrm{M} \mathrm{MCR}$ red1, $10 \mathrm{mM}$ methyl-SCoM and $1 \mathrm{mM} \mathrm{CoB}{ }_{5} \mathrm{SH}$ with $2 \mu \mathrm{l}$ of reservoir solution (100 $\mathrm{mM}$ Hepes-Na, $\mathrm{pH} 7.5,150 \mathrm{mM}\left(\mathrm{Mg}\left(\mathrm{CH}_{3} \mathrm{COO}\right)_{2}\right), 22 \%$ PEG 400). The crystals with bound $\mathrm{CoB}_{6} \mathrm{SH}$ and $\mathrm{CoB}_{9} \mathrm{SH}$ were obtained by co-crystallization of $1 \mathrm{mM}$ of analogue with $142 \mu \mathrm{M} \mathrm{MCR}_{\text {red } 1}$ and equilibrated with $2 \mu \mathrm{l}$ of reservoir solution (100 mM Hepes-Na, $\mathrm{pH}$ 7.5, $150 \mathrm{mM} \mathrm{Mg}\left(\mathrm{CH}_{3} \mathrm{COO}\right)_{2}, 20 \%$ PEG 400 for $\mathrm{CoB}_{6} \mathrm{SH}$ and $100 \mathrm{mM}$ Hepes-Na, $\mathrm{pH} 7.3$, $\left.150 \mathrm{mM} \mathrm{Mg}\left(\mathrm{CH}_{3} \mathrm{COO}\right)_{2}\right), 22 \%$ PEG 400 for $\left.\mathrm{CoB}_{9} \mathrm{SH}\right)$. Crystals were cryoprotected in reservoir solution containing $25 \%$ (v/v) PEG 400 by soaking for 2-5 minutes before cryocooling in liquid nitrogen in the anaerobic chamber. Crystals of $\mathrm{CoB}_{8} \mathrm{SH}$ bound to MCR were obtained by incubating $2 \mu \mathrm{l}$ of a mixture of $119 \mu \mathrm{M} \mathrm{MCR}_{\text {red1 } 1}$ and $1 \mathrm{mM} \mathrm{CoB}{ }_{8} \mathrm{SH}$ with $2 \mu \mathrm{l}$ of reservoir solution (100 mM Hepes-Na, $\left.\mathrm{pH} 7.3,150 \mathrm{mM} \mathrm{Mg}\left(\mathrm{CH}_{3} \mathrm{COO}\right)_{2}\right), 20 \%$ PEG 400). Before cryoprotection, the crystals were soaked for 5-10 minutes in a $100 \mathrm{mM}$ solution of methyl iodide ${ }^{2}$. The methyl iodide solution used for soaking was prepared by adding a concentrated stock of methanolic solution of methyl iodide to the reservoir 
solution. Soaked crystals were quickly cryoprotected as described above and cryocooled in the anaerobic chamber.

\section{X-ray Diffraction Data Collection, Processing and Refinement}

$\mathrm{X}$-ray diffraction data were collected at $100 \mathrm{~K}$ on a ADSC Quantum-315 detector at the APS Beamline 14-BM-C (BioCARS). The wavelength of X-rays was $0.979 \AA$ A. Data were processed using HKL2000 (50). As in the previous X-ray crystallographic studies, the crystals belong to the monoclinic space group $\mathrm{P} 2{ }_{1}\left(\mathrm{a}=82 \AA, \mathrm{b}=118 \AA, \mathrm{c}=122 \AA, \beta=92^{\circ}\right)$, with one MCR molecule (two active sites) per asymmetric unit $(5,33)$. For refinement, REFMAC in the Collaborative Computational Project Number 4 (CCP4) program suite was used (51). A random sample of $5 \%$ of the data across all resolution shells was chosen to check refinement progress through calculation of an $R_{\text {free }}$. The same reflections were used to calculate $R_{\text {free }}$ for all structures, thus preventing bias due to high structural identity. The remaining reflections were used in refinement $\left(R_{\text {work }}\right)$. Model building was done using the Crystallographic Object-Oriented Toolkit (COOT) (52). The diffraction data and their models are designated as $\mathrm{MCR}_{\mathrm{CoB} X S \mathrm{SH}}$, where $X$ is the number of carbons in the alkanoyl portion of the analogue. Library files in $\mathrm{CCP} 4$ for $\mathrm{F}_{430}$ and $\mathrm{CoBSH}$ were incorrect, and these were modified in Monomer Library Sketcher in the CCP4 program suite by comparison with schematic drawings from Grabarse et al. (33). Co-ordinate and CCP4 library files for the different CoBSH analogues were created in Monomer Library Sketcher. The general model building and refinement strategy for all structures was as follows. It was clear from the electron density in the substrate channel and at the active site that mixtures of species were present in all datasets. These could be visualized with Fo-Fc and Fo-Fo difference electron density maps (Supporting Information, Figure S1). The known positions of CoBSH and HSCoM from the published Ni(II)-MCR crystal structures (PDB codes $1 \mathrm{hbn}, 1 \mathrm{hbo}, 1 \mathrm{hbu}$ (33)) were used as guides to determine which species could be present in each dataset, and these were then simultaneously modeled into the electron density. By alteration of their relative occupancies (in 10\% increments) followed by refinement, the ratio of occupancy between different species was determined using the assumption that the average B-factors for all molecular species bound should be similar to that of $\mathrm{F}_{430}$ and adjacent well-ordered protein atoms within the active site and substrate channel. The combinations of modeled ligands were constantly reassessed throughout refinement based on the remaining difference electron density. This included test refinements of different ligand combinations during the latter stages, thus using the optimized phases to check whether a different combination of ligands could also explain the electron density. Sensible chemical structures and interactions, along with keeping the combined occupancies of sterically mutually exclusive species $\leq 100 \%$, were maintained throughout refinement. The model was finally accepted when the difference electron density map was minimal and the B-factors for the models converged.

In practice the first structure refined was that of $\mathrm{MCR}_{\mathrm{CoB} 5 \mathrm{SH}}$. Initial phases were generated by difference Fourier using a previously determined crystal structure (PDB code 1 mro (5)) but with all non-bonded molecules, including water, removed from the model except $\mathrm{F}_{430}$. Initial rigid body refinement followed by restrained refinement of $\mathrm{MCR}_{\mathrm{CoB} 5 \mathrm{SH}}$ reduced the $R_{\text {work }}$ to $26.5 \%$. After model building and subsequent rounds of restrained refinement the $R_{\text {work }}$ was $14.3 \%\left(R_{\text {free }} 16.6 \%\right)$. Of the five structures only the $\mathrm{CoB}_{5} \mathrm{SH}$ analogue is completely coincident with $\mathrm{CoBSH}$, and so particular care had to be used in teasing apart the ratios of the two species in modeling the $\mathrm{MCR}_{\mathrm{CoB} 5 \mathrm{SH}}$ electron density. This was done by

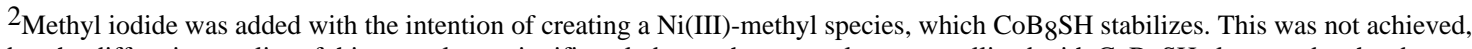
but the diffraction quality of this crystal was significantly better than crystals co-crystallized with $\mathrm{CoB}_{8} \mathrm{SH}$ alone, and so has been included in this study. 
initially refining $100 \%$ CoBSH in the substrate channel. Positive Fo-Fc difference density located at the carbon where the shorter $\mathrm{CoB}_{5} \mathrm{SH}$ thiol might be expected to be indicated the presence of a more electron-rich species than carbon, which is consistent with the presence of the $\mathrm{CoB}_{5} \mathrm{SH}$ sulfur. The refinement converged at a model containing a 50:50 mix of $\mathrm{CoBSH}$ and the analogue. However, positive Fo-Fc difference density was still present at the position of the $\mathrm{CoBSH}$ thiol, therefore a water molecule was added to the $\mathrm{CoB}_{5} \mathrm{SH}$ model at $50 \%$ occupancy and upon refinement this accounted for the electron density. An illustration of the electron density quality from this structure is shown in Supporting Information, Figure S2. An HSCoM-, CoBSH- and CoBSH analogue-free version of the refined $\mathrm{MCR}_{\mathrm{CoB5SH}}$ structure was used as the starting model to generate initial phases for the four other structures. After the initial round of restrained refinement the $R_{\text {work }}$ for these structures were reduced to $14.5-15.6 \%$.

\section{RESULTS AND DISCUSSION}

\section{Crystal Structures of MCR}

Five crystal structures were determined, four of which are in complex with CoBSH analogues differing in the number of carbons atoms in the alkanoyl portion of the molecule. CoBSH is an $N$-7-mercaptoheptanoyl-containing molecule, whereas the four CoBSH analogues contain $N$-5-mercaptopentanoyl-, $N$-6-mercaptohexanoyl-, $N$-8-mercaptooctanoylor $\mathrm{N}$-9-mercaptononanoyl-moieties (Figure 2). The corresponding crystal structures are designated as $\mathrm{MCR}_{\mathrm{CoBXSH}}$, where $X$ is the number of carbons in the alkanoyl portion of the analogue. The other crystal structure is of $\mathrm{MCR}_{\text {red1c-silent }}$ (MCR in the $\mathrm{Ni}$ (II) state in complex with $\mathrm{HSCoM}$, designated here as $\mathrm{MCR}_{\mathrm{HSCoM}}$ ) that is $\mathrm{CoBSH}$-depleted. The datasets have resolutions in the range from 1.35-1.8 $\AA$. Although the crystallizations were set up with the MCR solution predominantly in the $\mathrm{Ni}(\mathrm{I})-\mathrm{MCR}_{\text {red1 }}$ state, by the time X-ray diffraction data were collected they had been oxidized to the $\mathrm{Ni}(\mathrm{II})-\mathrm{MCR}_{\text {red1-silent }}$ state (Supporting Information). Following data collection there was no evidence for photoreduction of the $\mathrm{Ni}(\mathrm{II})$ back to $\mathrm{Ni}(\mathrm{I})$ in any of the crystals, as assessed by single crystal UV-visible microspectrophotometry (Supporting Information and Figure S3). Attempts to photoreduce the crystals using different wavelengths and temperatures were unsuccessful (Supporting Information).

Overall, the resulting structures are very similar to each other and to the previously published structures of MCR, with differences mainly localized to the active site and substrate channel. The two active sites in the ASU were refined independently. Unless otherwise stated there was no difference between them. All five datasets contain a mixture of species bound to the enzyme. There is always a background of CoBSH and HSCoM, which co-purify with MCR and cannot be fully removed by extensive buffer exchange or by the addition of a CoBSH analogue. HSCoM is added during purification of MCR, as it stabilizes the resting active $\mathrm{Ni}(\mathrm{I})$ state (unpublished data), and this leads to HSCoM occupancies between 50-100\% amongst the structures (Table 1). In contrast CoBSH, which is not added during purification, has occupancies ranging from $30-50 \%$. As these confounding species have all been described at high occupancy in other crystallographic studies, the structural data of interest could be isolated $(5,33)$. In each case, the additional electron density could be explained by inclusion of the appropriate $\mathrm{CoB}_{X} \mathrm{SH}$ model used in that experiment at $50 \%$ or higher occupancy. The resulting models, along with $2 \mathrm{Fo}-\mathrm{Fc}$ electron density, are shown in Figure 3 . The $R_{\text {work }}$ for the final structures range from 13.0 to $15.0 \%\left(R_{\text {free }} 15.5\right.$ to $\left.19.5 \%\right)$. The X-ray data collection, processing, refinement and model building statistics are given in Table 1. 


\section{Analogues shorter than $\mathrm{CoBSH} ; \mathrm{CoB}_{5} \mathrm{SH}$ and $\mathrm{CoB}_{6} \mathrm{SH}$}

$\mathrm{CoB}_{5} \mathrm{SH}$ is two methylene groups shorter than $\mathrm{CoBSH}$, the MCR substrate. The $\mathrm{MCR}_{\mathrm{CoB} 5 \mathrm{SH}}$ structure is to $1.35 \AA$ resolution. As expected the pentanoyl chain follows the path of the CoBSH heptanoyl carbons down the substrate channel, and thus its thiol is positioned in the same place as the second carbon preceding the CoBSH thiol (Figure 3A and 4). There are no published MCR kinetic studies using $\mathrm{CoB}_{5} \mathrm{SH}$, but as it binds in the substrate channel, it is likely to be an inhibitor.

$\mathrm{CoB}_{6} \mathrm{SH}$ is one methylene shorter than $\mathrm{CoBSH}$, and is a slow substrate of MCR. In this case the $1.4 \AA$ resolution electron density of $\mathrm{MCR}_{\mathrm{CoB} 6 \mathrm{SH}}$ indicates that the analogue unexpectedly binds in the substrate channel such that its thiol is virtually in the same position as the thiol of CoBSH (Figure 3B and 4). The hexanoyl chain is oriented so that it takes a shorter route down the substrate channel between carbons 2 and 5 (with the carbonyl carbon labeled as carbon 1) than CoBSH (Figure 4, Supporting Information, Figure S4). This short-cut is not seen in any of the other $\mathrm{CoB}_{X} \mathrm{SH}$ complex crystal structures, but presumably arises because this $\mathrm{CoB}_{6} \mathrm{SH}$ binding conformer is energetically more favorable, although it is not clear from the structure why this might be the case. $\mathrm{CoB}_{6} \mathrm{SH}$ binds very tightly to MCR, with an apparent $K_{\mathrm{i}}$ value of $0.1 \mu \mathrm{M}(3)$.

\section{Water structure in the absence of HSCoM}

The electron density for the $\mathrm{MCR}_{\mathrm{CoB} 6 \mathrm{SH}}$ crystal structure only supported the modeling of 50 $\%$ bound HSCoM. In the fraction of MCR molecules where HSCoM is absent, the HSCoM binding site is occupied by a network of four water molecules (Supporting Information, Figure S5). Two waters are positioned close to the absent sulfonate oxygen positions of HSCoM. Based on the presence of positive difference electron density, a third water was modeled ligated to the $\mathrm{Ni}$, and refined to a distance of $\sim 2 \AA(2.0 \AA$ and $2.1 \AA$ in the two active sites of the ASU) with no distance restraint imposed between the $\mathrm{Ni}$ and water. This water is in a similar position as the $\mathrm{Ni}$ coordinating sulfonate oxygen of the heterodisulfide product in $\mathrm{MCR}_{\text {silent }}$ (Supporting Information, Figure S6 and PDB codes 3m32, 1hbm) (5, 33). The fourth water was in the vicinity of the expected position of a bridging water (W1) seen in other structures (Figure 1, 3A and 3C).

\section{Water structure in the absence of CoBSH}

The $1.45 \AA$ A resolution electron density obtained for $\mathrm{MCR}_{\mathrm{HSCOM}}$ indicates that the substrate channel contains only $30 \% \mathrm{CoBSH}$. Nine ordered waters (W1-W9), along with an acetate ion from the crystallization solution occupy the channel, with the acetate positioned where the phosphothreonine linkage of CoBSH would be (Figure 3C). Presumably 1-2 further waters would replace the acetate under physiological conditions. Other than W3 and W7, the waters form hydrogen bonds with protein (Figure 5). One water (W2) occupies the same site as the CoBSH thiol. Presumably due to the loss of favorable interactions that exist when CoBSH is present, the hydrophobic side-chain of Vala482 adopts a second conformation modeled at $60 \%$ occupancy (Supporting Information, Figure S7).

\section{Position of the "bridging" water, W1}

The equivalent of $\mathrm{W} 1$ has previously been observed in $\mathrm{MCR}_{\mathrm{red1} \text {-silent }}$ and $\mathrm{MCR}_{\text {ox1-silent }}$ crystal structures where, in the presence of CoBSH and HSCoM, it is sited equidistant (3.2 $\AA$ ) between the two coenzyme thiols (PDB codes: $1 \mathrm{hbn}, 1 \mathrm{hbo}, 1 \mathrm{hbu}$ ) and thus been termed the "bridging water" (Figure 1) $(5,33)$. However, in the $\mathrm{MCR}_{\mathrm{HSCoM}}$ structure, due to the presence of the more polarized W2 water, W1 is displaced away from HSCoM to maximize the hydrogen bond interaction with W2 (2.9 ̊ to W2; $3.5 \AA$ to HSCoM thiol, Figure 5). In the $\mathrm{MCR}_{\mathrm{CoB} 5 \mathrm{SH}}$ structure that also contained $\mathrm{W} 2$, the electron density indicated that this 
repositioning of $\mathrm{W} 1$ towards $\mathrm{W} 2$ also occurred. In contrast, the $\mathrm{MCR}_{\mathrm{CoB} 6 \mathrm{SH}}$ structure contained $100 \%$ thiol at the CoBSH position, but a partial occupancy of HSCoM (50\%). In this case the electron density for $\mathrm{W} 1$ indicated it had moved towards the nickel to form an optimal hydrogen bond with a Ni-ligating water that was only present in the absence of $\operatorname{HSCoM}\left(3.7 \AA\right.$ to $\mathrm{CoB}_{(6)} \mathrm{SH}$ thiol; $3.0 \AA$ to Ni-ligating water, Supporting Information, Figure S5). In all structures reported here, W1 (if present) appears to be a sensitive indicator of the relative electronegativity of the Ni-ligated atom to that occupying the position of the CoBSH thiol, and was a useful check in the crystallographic modeling and refinement process.

\section{Flexibility in the substrate channel: Alternative protein conformers}

The binding site of HSCoM (and presumably methyl-SCoM) is more deeply buried within the enzyme, and so it must enter prior to CoBSH for productive chemistry to occur. As binding of CoBSH in the absence of co-substrate would be inhibitory, it was suggested that a conformational change upon methyl-SCoM binding might lower the $K_{\mathrm{d}}$ for $\mathrm{CoBSH}$, and thus promote an ordered mechanism. Compared to the $1 \mathrm{hbn} \mathrm{MCR}_{\mathrm{ox} 1 \text {-silent }}$ and $1 \mathrm{hbu}$ $\mathrm{MCR}_{\text {red1-silent }}$ crystal structures, which both have full occupancy HSCoM, the lower occupancy of $\mathrm{HSCoM}$ in the 1 hbo $\mathrm{MCR}_{\text {red1-silent }}$ structure was associated with significantly greater flexibility within the channel, and the ability to model a second conformation of a Gly-rich amino acid stretch that formed part of the CoBSH channel. This suggested that methyl-SCoM binding might cause the channel to become more ordered, increasing the affinity of MCR for CoBSH by conformational restriction rather than a switch mechanism where the structure reorganizes from one well-defined conformer to another (33). In the $\mathrm{MCR}_{\mathrm{HSCoM}}$ data containing $30 \% \mathrm{CoBSH}$ and $100 \% \mathrm{HSCoM}$, the Fo-Fc difference electron density map at one of the two independent active sites in the ASU contained positive peaks that suggested the presence of an alternate conformation also involving this part of the polypeptide (Supporting Information, Figure S8). Using this as a guide, a similar second conformation involving seven contiguous amino acid residues of the same Gly-rich amino acid stretch ( $\beta 366-372)$ could be modeled and refined at $20 \%$ occupancy leaving no residual difference density. Parts of the $\alpha^{\prime}$ subunit ( $\alpha^{\prime} 111-129$ and $\left.\alpha^{\prime} 237-242\right)$ that are in close proximity to this stretch of amino acids also exhibit second conformations, with the main-chain carbonyl of $\alpha^{\prime} 243$ in van der Waals contact with the $B$ ring of $F_{430}$ tetrapyrrole (Supporting Information, Figure S9). Modeling these at 20\% occupancy accounted for the weak positive Fo-Fc difference electron density peaks observed in these areas. The evidence of alternate conformers in these areas lends support to the proposal that increased flexibility in the substrate channel propagates through the protein (33).

The $\mathrm{MCR}_{\mathrm{CoB} 6 \mathrm{SH}}$ crystal structure contains $50 \% \mathrm{CoB}_{6} \mathrm{SH}, 50 \% \mathrm{CoBSH}$ and $50 \% \mathrm{HSCoM}$. In this case there is no evidence of an alternate loop conformation in either active site of the ASU. However, as $\mathrm{CoBSH}$ and $\mathrm{CoB}_{6} \mathrm{SH}$ combined are at $100 \%$ occupancy, it is not surprising their favorable interactions with the substrate channel would reduce conformational disorder, despite the partial occupancy of HSCoM.

\section{Analogues longer than $\mathrm{CoBSH} ; \mathrm{CoB}_{8} \mathrm{SH}$ and $\mathrm{CoB}_{9} \mathrm{SH}$}

Both analogues could be accommodated in the MCR substrate channel (Figures 3D and 3E). The electron density supported final models containing $50 \% \mathrm{CoB}_{8} \mathrm{SH}$ for $\mathrm{MCR}_{\mathrm{CoB} 8 \mathrm{SH}}(1.8$ $\AA$ A resolution) and $60 \% \mathrm{CoB}_{9} \mathrm{SH}$ for $\mathrm{MCR}_{\mathrm{CoB} 9 \mathrm{SH}}(1.45 \AA$ resolution). The phosphate headgroups are in identical positions to those of $\mathrm{CoBSH}, \mathrm{CoB}_{5} \mathrm{SH}, \mathrm{CoB}_{6} \mathrm{SH}$ (Figure 4) (5, 33). Both analogues follow the crystallographically observed chain path of bound $\mathrm{CoBSH}$, with the extra atoms displacing the W1 water and placing the thiols closer to the nickel (Figure 6). $\mathrm{CoB}_{9} \mathrm{SH}$ does have a second conformer that deviates from the $\mathrm{CoBSH}$ path, but the thiol position for this conformer and the CoBSH-tracking conformer are identical (Figure 3E and 
Supporting Information, Figure S10). Interestingly, the thiol of $\mathrm{CoB}_{8} \mathrm{SH}$ is not coincident with the $\mathrm{CoB}_{9} \mathrm{SH}$ carbon that precedes the $\mathrm{CoB}_{9} \mathrm{SH}$ thiol (Figure 6). $\mathrm{CoB}_{8} \mathrm{SH}$ is an MCR

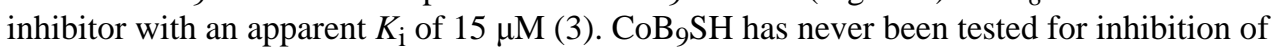
MCR-catalyzed methane formation, but it is reasonable to assume that it would be an inhibitor.

\section{$\mathrm{CoB}_{X} \mathrm{SH}$ thiol-to-nickel spatial relationship}

The position of CoBSH in previous crystal structures poses a conundrum $(5,33)$. In all the proposed catalytic mechanisms, CoBSH must interact with species generated at the nickel. Perplexingly, the sulfur of the CoBSH substrate is $8.8 \AA$ from the $\mathrm{Ni}$ (II) in the $\mathrm{MCR}_{\text {ox1-silent }}$ and both $\mathrm{MCR}_{\text {red1-silent }}$ crystal structures, and $6.4 \AA$ from the thiol of the substrate analogue HSCoM (Figure 1). Modeling studies demonstrated that the addition of a methyl group to HSCoM did not bridge this gap $(35,45,53)$. Therefore, a conformational change has been postulated that would enable CoBSH to penetrate deeper into the substrate channel, and thus approach closer to any nickelbound species. The heterodisulfide product in the $\mathrm{MCR}_{\text {silent }}$ crystal structure has the CoBSH portion in virtually the same place as in $\mathrm{MCR}_{\mathrm{Ox} 1-\text { silent }}$, giving no clue to possible structural changes that might occur to facilitate CoBSH reacting with nickel-associated intermediates $(5,33)$.

Trigonometry suggests that if the alkanoyl chain of CoBSH or its analogue is in an extended conformation, each additional unit in the chain would lead to the thiol moving $\sim 1.2 \AA$ towards the Ni. Until this study there have been no crystal structures of CoBSH analogues in complex with MCR, so mechanistic studies using different chain length analogues of $\mathrm{CoBSH}$ assumed that shorter analogues would trace the observed path of $\mathrm{CoBSH}$, and longer analogues would penetrate about $\sim 1.2 \AA$ deeper per additional chain unit into the channel. In the case of the shortest analogue $\mathrm{CoB}_{5} \mathrm{SH}$, it does indeed follow the path of $\mathrm{CoBSH}$, with the thiol of $\mathrm{CoB}_{5} \mathrm{SH}$ being $2.8 \AA$ away from the thiol position of $\mathrm{CoBSH}$. However, due to the conformation CoBSH adopts when bound in the substrate channel, the difference in the $\mathrm{S}-\mathrm{Ni}$ distance is small; the $\mathrm{CoB}_{5} \mathrm{SH}$ thiol being only $0.5 \AA$ farther from the $\mathrm{Ni}$ than CoBSH ( $8.8 \AA$ for $\mathrm{CoBSH} v$ s. $9.3 \AA$ for $\mathrm{CoB}_{5} \mathrm{SH}$ ) (Table 2). This is due to the alkanoyl chain of CoBSH not being in an extended conformation from carbons 4 to 6 (carbon 1 is the carbonyl carbon). $\mathrm{CoB}_{6} \mathrm{SH}$ on the other hand adopts a conformation that places its thiol in virtually the same position as the thiol of $\mathrm{CoBSH}$ (Figure 4 and Table 2). This is consistent with $\mathrm{CoB}_{6} \mathrm{SH}$ being a substrate. However, the $k_{\text {cat }}$ is 1000 -fold lower than for CoBSH $(3,35)$ although its $K_{\mathrm{m}}$ value $(180 \mu \mathrm{M}$, Dey \& Ragsdale, in preparation) is similar to that of CoBSH $\left(K_{\mathrm{m}}=75 \mu \mathrm{M}(3)\right)$. The reason for this may be that the shorter alkanoyl chain may not enable the analogue thiol to approach the nickel close enough for efficient catalysis, and thus explain why $\mathrm{CoB}_{6} \mathrm{SH}$ is such a poor substrate.

In the case of the longer $\mathrm{CoB}_{X} \mathrm{SH}$ analogues, the sulfur of $\mathrm{CoB}_{8} \mathrm{SH}$ is $2.6 \AA$ closer to the $\mathrm{Ni}$ ion of $\mathrm{F}_{430}$ than that of $\mathrm{CoBSH}$, and $2.5 \AA$ closer to the thiol of HSCoM (Figure 6 and Table 2). The $\mathrm{CoB}_{9} \mathrm{SH}$ molecule follows the path of $\mathrm{CoBSH}$, and reaches only a little further into the substrate channel than $\mathrm{CoB}_{8} \mathrm{SH}$, with the $\mathrm{CoB}_{9} \mathrm{SH}$ thiol positioned $2.9 \AA$ closer to the $\mathrm{Ni}$ than the thiol of CoBSH (Figure 6 and Table 2). This is only $0.3 \AA$ closer than the distance observed for the $\mathrm{CoB}_{8} \mathrm{SH}$ thiol, even though they are non-coincident. The distance to the thiol of HSCoM is $2.6 \AA$ closer than that of the substrate, CoBSH; only $0.1 \AA$ closer than the $\mathrm{CoB}_{8} \mathrm{SH}$ thiol. The two analogue thiols are above an annular hydrophobic aromatic environment created by Phe $\alpha 330$, Tyr $\alpha 333$, Phe $\alpha 443$, Phe $\beta 361$ and Tyr $\beta 367$ that lies between them and $\mathrm{F}_{430}$ (Figure 6). As a result, penetrating further into the channel may be energetically unfavorable, consistent with the small difference in relative distances between the $\mathrm{CoB}_{8} \mathrm{SH} / \mathrm{CoB}_{9} \mathrm{SH}$ thiols and the $\mathrm{HSCoM}$ thiol/ $/ \mathrm{F}_{430}$ nickel. The annulus is proposed to be catalytically important in positioning methyl-SCoM and stabilizing the methane product, 
and the tyrosines have been proposed to be proton donors associated with mechanism II (Scheme 2B) $(5,33)$.

Thus, there appear to be three preferential distances for thiols (including that of HSCoM) within the MCR substrate channel; HSCoM at $2.4 \AA, \mathrm{CoB}_{6} \mathrm{SH} / \mathrm{CoBSH}$ at $8.7-8.8 \AA$ and $\mathrm{CoB}_{8} \mathrm{SH} / \mathrm{CoB}_{9} \mathrm{SH}$ at $5.9-6.2 \AA$ from the nickel of $\mathrm{F}_{430}$ (Table 2).

Recent ENDOR, high-field continuous and pulse EPR work has identified changes in nickel co-ordination when CoBSH is added to $\mathrm{MCR}_{\text {red } 1 \mathrm{c}}$ (active $\left.\mathrm{Ni}(\mathrm{I})-\mathrm{MCR}_{\text {red } 1}+\mathrm{HSCoM}\right)(14$, $15,18,31)$. This generates up to $50 \% \mathrm{MCR}_{\mathrm{red} 2}$ which is comprised of two distinct nickel coordination geometries; an axial $\mathrm{MCR}_{\text {red2a }}$ formally assigned as a $\mathrm{Ni}(\mathrm{III})$-hydride, and a rhombic $\mathrm{MCR}_{\text {red2r }}$ in which the thiol of HSCoM is a Ni(I) ligand (Supporting Information, Scheme S1). Formation of $\mathrm{MCR}_{\text {red2 }}$ could also be induced by addition of CoBSH substrate analogues $\mathrm{CoBS}-\mathrm{CH}_{3}$ and $\mathrm{CoBS}-\mathrm{CF}_{3}$, which have a chain length one unit longer than substrate $\mathrm{CoBSH}(18,53)$. The $\mathrm{CoBS}-\mathrm{CF}_{3}$ enabled ${ }^{19} \mathrm{~F}-\mathrm{ENDOR}$ studies to be performed, and demonstrated that following $\mathrm{CoBS}-\mathrm{CF}_{3}$ addition the remaining $\mathrm{MCR}_{\text {red } 1}$ species had $\mathrm{Ni}(\mathrm{I})-{ }^{19} \mathrm{~F}$ distances of $6.2-7.7 \AA$. This distance range agreed with a $\mathrm{CoBS}_{-}-\mathrm{CF}_{3}$ model created using the $\mathrm{CoBSH}$ position observed in the $\mathrm{MCR}_{\mathrm{ox} 1 \text {-silent }}$ crystal structure (53). However, in the $\mathrm{MCR}_{\text {red2 }}$ species the $\mathrm{Ni}(\mathrm{I}){ }^{19} \mathrm{~F}$ distances had shortened indicating a movement of $\sim 2 \AA$ towards the nickel $\left(\mathrm{MCR}_{\text {red2a }} \mathrm{Ni}(\mathrm{I})-{ }^{19} \mathrm{~F}, 4.0-5.5 \AA ; \mathrm{MCR}_{\text {red2r }}\right.$ $\mathrm{Ni}(\mathrm{I})-{ }^{19} \mathrm{~F}, 4.5-5.7 \AA$ ). In the case of the $\mathrm{CoB}_{8} \mathrm{SH}$ analogue (the closest equivalent to CoBS$\mathrm{CF}_{3}$ used in this study) the thiol to $\mathrm{Ni}(\mathrm{II})$ distance lies between the distance ranges observed in the $\mathrm{CoBS}-\mathrm{CF}_{3}$ studies, and so the fluorine(s) of the $\mathrm{CoBS}-\mathrm{CF}_{3}$ in $\mathrm{MCR}_{\text {red2 } 2}$ might penetrate a little further into the hydrophobic annulus in the $\mathrm{MCR}_{\text {red2 }}$ species. As the alkanoyl chain of CoBSH is not fully extended it could easily undergo a similar conformation change to that observed in the $\mathrm{MCR}_{\text {red2 }}$ state.

\section{Reaction of MCR Ni(III)-alkyl species' with $\mathrm{CoB}_{8} \mathrm{SH}$ and $\mathrm{CoB}_{9} \mathrm{SH}$}

The two longer $\mathrm{CoB}_{X} \mathrm{SH}$ analogues have been shown to undergo alkylation when reacted with $\mathrm{MCR}_{\mathrm{PS}}$, a [Ni(III)-alkyl $\leftrightarrow \mathrm{Ni}(\mathrm{II})$-alkylsulfonate radical] formed from reaction of $\mathrm{Ni}(\mathrm{I})-\mathrm{MCR}_{\text {red1 }}$ with bromopropanesulfonate (BPS) (Supporting Information, Scheme S1) $(20,23,30,45,54)$. BPS is a substrate of $\mathrm{MCR}_{\text {red } 1}$ in a reaction that involves a rapid CoBSH-independent nucleophilic attack by $\mathrm{Ni}(\mathrm{I})$ on BPS to displace bromide and generate $\mathrm{MCR}_{\mathrm{PS}}$ at a rate $\sim 60$-fold faster than generation of methane from CoBSH and methyl$\operatorname{HSCoM}(20,45)$. Certain thiols can eliminate the propylsulfonate to yield a thioether product and regenerate $\mathrm{MCR}_{\text {red } 1}$, although at a rate 1000 -fold slower than methane formation (45). Both $\mathrm{CoB}_{8} \mathrm{SH}$ and $\mathrm{CoB}_{9} \mathrm{SH}$ can react with $\mathrm{MCR}_{\mathrm{PS}}$ to regenerate $\mathrm{MCR}_{\text {red1 }}$, but CoBSH cannot. The overall second-order rate constant for the reactivation of MCR by $\mathrm{CoB}_{8} \mathrm{SH}$ is $160 \mathrm{M}^{-1} \mathrm{~s}^{-1}$, whereas for $\mathrm{CoB}_{9} \mathrm{SH}$ the reaction is more sluggish $\left(12 \mathrm{M}^{-1} \mathrm{~s}^{-1}\right)$. $\mathrm{CoB}_{9} \mathrm{SH}$ might be expected to be closer to the proximal Ni ligand. It was therefore proposed that this caused steric interference and explained why $\mathrm{CoB}_{9} \mathrm{SH}$ was a poorer reactivator of MCR than $\mathrm{CoB}_{8} \mathrm{SH}$. Our study has shown that the thiols of these two analogues are placed such that they are approximately the same distance $(\sim 3.7 \AA)$ from the thiol of HSCoM ligated to the Ni atom (Table 2). The Ni(II)-HSCoM bond is $2.4 \AA$, whereas an Ni(III)-alkyl bond is expected to be $\sim 2 \AA(24,33)$, thus indicating that a conformational change is required to effect the nucleophilic attack of the $\mathrm{CoB}_{8} \mathrm{SH}$ and $\mathrm{CoB}_{9} \mathrm{SH}$ thiols on an alkylbound species. It would thus appear that a conformational change, such as observed in $\mathrm{MCR}_{\mathrm{red} 2}$, is required for this chemistry also (53).

A Ni(III)-alkyl species is akin to the first intermediate in mechanism I of MCR-catalyzed methane formation, $\mathrm{Ni}(\mathrm{III})$-methyl $\left(\mathrm{MCR}_{\mathrm{Me}}\right.$, Supporting Information, Scheme S1, Scheme $2 \mathrm{~A})(11,27)$. $\mathrm{MCR}_{\mathrm{Me}}$ has been shown to be capable of generating $\mathrm{MCR}_{\text {red1 }}$ and methylSCoM upon addition of HSCoM (which is the reverse of mechanism I, step 1, Scheme 2A); 
similar chemistry to the observed formation of a thioether product from the Ni(III)-alkyl. Further addition of CoBSH following HSCoM treatment of $\mathrm{MCR}_{\mathrm{Me}}$ led to methane and heterodisulfide formation, the natural products of methanogenesis. Although this lends credence to mechanism I, it should be noted that like $\mathrm{MCR}_{\mathrm{PS}}, \mathrm{MCR}_{\mathrm{Me}}$ in these experiments was generated artificially. However, the $\mathrm{MCR}_{\mathrm{CoB} 9 \mathrm{SH}}$ crystal structure demonstrates that the two additional methylene units in the alkanoyl chain $c$.f. CoBSH, do not necessarily translate into direct interaction of the thiol with the nickel proximal ligand. However, this could represent the favorable position for a $\mathrm{CoBSH}$ thiol interacting with the methyl group of methyl-SCoM. Just as the alkanoyl chain of $\mathrm{CoB}_{6} \mathrm{SH}$ has a more extended conformation than $\mathrm{CoBSH}$ in the substrate channel, CoBSH could also adopt a more extended conformation so that its thiol was in a similar position as the thiol of $\mathrm{CoB}_{8} \mathrm{SH}$, priming it for reaction with a nickel bound species.

If a significant conformational change is required early in MCR-catalyzed chemistry, which would be a requirement of mechanism I, catalysis may well involve a rearrangement of the aromatic amino acid annulus due to the presence of the methyl of methyl-SCoM, and this might enable deeper penetration of CoBSH into MCR (Figure 6). All the crystal structures in this study, and those solved previously, are of the inactive $\mathrm{Ni}(\mathrm{II})$-MCR, which disfavors close approach to the nickel in the absence of $\mathrm{Ni}(\mathrm{I})$-bound methyl-SCoM, even in the case of $\mathrm{CoB}_{9} \mathrm{SH}$.

\section{Conclusion}

The goal of this study was to induce structural changes within the substrate channel and active site of MCR using analogues of coenzyme CoBSH. It was hoped that this would shed light on the nature of conformational changes that have been proposed to occur in MCR catalysis. We have shown that that the $\mathrm{CoB}_{X} \mathrm{SH}$ analogues do not lead to any significant conformational changes within the context of inactive Ni(II)-MCR. Therefore, it may be that methyl-SCoM is the key coenzyme, in combination with a nickel oxidation state of 1 (and 3 ), that triggers a conformational change bringing the thiol of CoBSH closer to the nickel. Thus, the crystal structure of the $\mathrm{Ni}(\mathrm{I})$-methyl-SCoM/MCR complex may be required to structurally define the conformational changes required for MCR-mediated chemistry.

\section{Supplementary Material}

Refer to Web version on PubMed Central for supplementary material.

\section{Acknowledgments}

$\mathrm{X}$-ray data were collected at beam-line 14-BM-C and photoreduction studies at 14-ID-B, BioCARS at the Advanced Photon Source (APS), Argonne National Laboratory, Argonne, IL. We thank Vukica Srajer and YuSheng Chen for valuable assistance during data collection. Use of the Advanced Photon Source was supported by the U.S. Department of Energy, Basic Energy Sciences, Office of Science under Contract No. DEAC02-06CH11357. Use of the BioCARS Sector 14 was supported by the National Institutes of Health, National Center for Research Resources, under grant number RR007707. Computer resources were provided by the Basic Sciences Computing Laboratory of the University of Minnesota Supercomputing Institute, and we thank Can Ergenekan for his support. We also thank Ed Hoeffner at the Kahlert Structural Biology Laboratory (KSBL) at the University of Minnesota. Use of the KSBL was supported by a Minnesota Partnership for Biotechnology and a Medical Genomics Grant SPAP-05-0013-P-FY06.

\section{References}

1. Thauer RK. Biochemistry of methanogenesis: a tribute to Marjory Stephenson. Microbiology. 1998; 144:2377-2406. [PubMed: 9782487]

2. Thauer RK, Shima S. Methane as fuel for anaerobic microorganisms. Ann N Y Acad Sci. 2008; 1125:158-170. [PubMed: 18096853] 
3. Ellermann J, Hedderich R, Bocher R, Thauer RK. The final step in methane formation. Investigations with highly purified methyl-CoM reductase (component $\mathrm{C}$ ) from Methanobacterium thermoautotrophicum (strain Marburg). Eur J Biochem. 1988; 172:669-677. [PubMed: 3350018]

4. Ellefson WL, Wolfe RS. Component $\mathrm{C}$ of the methylreductase system of Methanobacterium. J Biol Chem. 1981; 256:4259-4262. [PubMed: 6783657]

5. Ermler U, Grabarse W, Shima S, Goubeaud M, Thauer RK. Crystal structure of methyl-coenzyme M reductase: the key enzyme of biological methane formation. Science. 1997; 278:1457-1462. [PubMed: 9367957]

6. Diekert G, Gilles HH, Jaenchen R, Thauer RK. Incorporation of 8 succinate per mol nickel into factors F430 by Methanobacterium thermoautotrophicum. Arch Microbiol. 1980; 128:256-262. [PubMed: 7212929]

7. Diekert G, Jaenchen R, Thauer RK. Biosynthetic evidence for a nickel tetrapyrrole structure of factor $\mathrm{F}_{430}$ from Methanobacterium thermoautotrophicum. FEBS Letters. 1980; 119:118-120. [PubMed: 7428919]

8. Whitman WB, Wolfe RS. Presence of nickel in Factor F430 from Methanobacterium bryantii. Biochem Biophys Res Comm. 1980; 92:1196-1201. [PubMed: 7370029]

9. Albracht SPJ, Ankel-Fuchs D, Böcher R, Ellermann J, Moll J, van der Zwann JW, Thauer RK. Five new EPR signals assigned to nickel in methyl-coenzyme $\mathrm{M}$ reductase from Methanobacterium thermoautotrophicum, strain Marburg. Biochim Biophys Acta. 1988; 955:86-102.

10. Dey M, Kunz RC, Lyons DM, Ragsdale SW. Characterization of alkyl-nickel adducts generated by reaction of methyl-coenzyme $m$ reductase with brominated acids. Biochemistry. 2007; 46:1196911978. [PubMed: 17902704]

11. Dey M, Telser J, Kunz RC, Lees NS, Ragsdale SW, Hoffman BM. Biochemical and spectroscopic studies of the electronic structure and reactivity of a methyl-Ni species formed on methylcoenzyme M reductase. J Am Chem Soc. 2007; 129:11030-11032. [PubMed: 17711283]

12. Duin EC, Cosper NJ, Mahlert F, Thauer RK, Scott RA. Coordination and geometry of the nickel atom in active methyl-coenzyme $\mathrm{M}$ reductase from Methanothermobacter marburgensis as detected by X-ray absorption spectroscopy. J Biol Inorg Chem. 2003; 8:141-148. [PubMed: 12459909]

13. Duin EC, Signor L, Piskorski R, Mahlert F, Clay MD, Goenrich M, Thauer RK, Jaun B, Johnson MK. Spectroscopic investigation of the nickel-containing porphinoid cofactor $\mathrm{F}(430)$. Comparison of the free cofactor in the $(+) 1,(+) 2$ and $(+) 3$ oxidation states with the cofactor bound to methylcoenzyme M reductase in the silent, red and ox forms. J Biol Inorg Chem. 2004; 9:563-576. [PubMed: 15160314]

14. Finazzo C, Harmer J, Bauer C, Jaun B, Duin EC, Mahlert F, Goenrich M, Thauer RK, Van Doorslaer S, Schweiger A. Coenzyme B induced coordination of coenzyme M via its thiol group to Ni(I) of F430 in active methyl-coenzyme M reductase. J Am Chem Soc. 2003; 125:4988-4989. [PubMed: 12708843]

15. Finazzo C, Harmer J, Jaun B, Duin EC, Mahlert F, Thauer RK, Van Doorslaer S, Schweiger A. Characterization of the MCRred2 form of methyl-coenzyme M reductase: a pulse EPR and ENDOR study. J Biol Inorg Chem. 2003; 8:586-593. [PubMed: 12624730]

16. Goubeaud M, Schreiner G, Thauer RK. Purified methyl-coenzyme-M reductase is activated when the enzyme-bound coenzyme F430 is reduced to the nickel(I) oxidation state by titanium(III) citrate. Eur J Biochem. 1997; 243:110-114. [PubMed: 9030728]

17. Harmer J, Finazzo C, Piskorski R, Bauer C, Jaun B, Duin EC, Goenrich M, Thauer RK, Van Doorslaer S, Schweiger A. Spin density and coenzyme M coordination geometry of the ox 1 form of methyl-coenzyme M reductase: a pulse EPR study. J Am Chem Soc. 2005; 127:17744-17755. [PubMed: 16351103]

18. Harmer J, Finazzo C, Piskorski R, Ebner S, Duin EC, Goenrich M, Thauer RK, Reiher M, Schweiger A, Hinderberger D, Jaun B. A nickel hydride complex in the active site of methylcoenzyme m reductase: implications for the catalytic cycle. J Am Chem Soc. 2008; 130:1090710920. [PubMed: 18652465] 
19. Hinderberger D, Ebner S, Mayr S, Jaun B, Reiher M, Goenrich M, Thauer RK, Harmer J. Coordination and binding geometry of methyl-coenzyme $\mathrm{M}$ in the red $1 \mathrm{~m}$ state of methylcoenzyme M reductase. J Biol Inorg Chem. 2008; 13:1275-1289. [PubMed: 18712421]

20. Kunz RC, Horng YC, Ragsdale SW. Spectroscopic and kinetic studies of the reaction of bromopropanesulfonate with methyl-coenzyme M reductase. J Biol Chem. 2006; 281:3466334676. [PubMed: 16966321]

21. Mahlert F, Bauer C, Jaun B, Thauer RK, Duin EC. The nickel enzyme methyl-coenzyme M reductase from methanogenic archaea: In vitro induction of the nickel-based MCR-ox EPR signals from MCR-red2. J Biol Inorg Chem. 2002; 7:500-513. [PubMed: 11941508]

22. Mahlert F, Grabarse W, Kahnt J, Thauer RK, Duin EC. The nickel enzyme methyl-coenzyme M reductase from methanogenic archaea: in vitro interconversions among the EPR detectable MCRred1 and MCR-red2 states. J Biol Inorg Chem. 2002; 7:101-112. [PubMed: 11862546]

23. Rospert S, Voges M, Berkessel A, Albracht SP, Thauer RK. Substrate-analogue-induced changes in the nickel-EPR spectrum of active methyl-coenzyme-M reductase from Methanobacterium thermoautotrophicum. Eur J Biochem. 1992; 210:101-107. [PubMed: 1332856]

24. Sarangi R, Dey M, Ragsdale SW. Geometric and electronic structures of the Ni(I) and methyl$\mathrm{Ni}(\mathrm{III})$ intermediates of methyl-coenzyme M reductase. Biochemistry. 2009; 48:3146-3156. [PubMed: 19243132]

25. Tang Q, Carrington PE, Horng YC, Maroney MJ, Ragsdale SW, Bocian DF. X-ray absorption and resonance Raman studies of methyl-coenzyme $\mathrm{M}$ reductase indicating that ligand exchange and macrocycle reduction accompany reductive activation. J Am Chem Soc. 2002; 124:13242-13256. [PubMed: 12405853]

26. Telser J, Davydov R, Horng YC, Ragsdale SW, Hoffman BM. Cryoreduction of methyl-coenzyme $\mathrm{M}$ reductase: EPR characterization of forms, MCR(ox1) and MCR (red1). J Am Chem Soc. 2001; 123:5853-5860. [PubMed: 11414817]

27. Yang N, Reiher M, Wang M, Harmer J, Duin EC. Formation of a nickel-methyl species in methylcoenzyme M reductase, an enzyme catalyzing methane formation. J Am Chem Soc. 2007; 129:11028-11029. [PubMed: 17711279]

28. Albracht SPJ, Ankelfuchs D, Vanderzwaan JW, Fontijn RD, Thauer RK. A New ElectronParamagnetic-Res Signal of Nickel in Methanobacterium-Thermoautotrophicum. Biochim Biophys Acta. 1986; 870:50-57.

29. Telser J, Horng YC, Becker DF, Hoffman BM, Ragsdale SW. On the assignment of nickel oxidation states of the Ox1, Ox2 forms of methyl-coenzyme M reductase. J Am Chem Soc. 2000; 122:182-183.

30. Hinderberger D, Piskorski RR, Goenrich M, Thauer RK, Schweiger A, Harmer J, Jaun B. A nickelalkyl bond in an inactivated state of the enzyme catalyzing methane formation. Angewandte Chemie-International Ed. 2006; 45:3602-3607.

31. Kern DI, Goenrich M, Jaun B, Thauer RK, Harmer J, Hinderberger D. Two sub-states of the red2 state of methyl-coenzyme M reductase revealed by high-field EPR spectroscopy. J Biol Inorg Chem. 2007; 12:1097-1105. [PubMed: 17690920]

32. Becker DF, Ragsdale SW. Activation of methyl-SCoM reductase to high specific activity after treatment of whole cells with sodium sulfide. Biochemistry. 1998; 37:2639-2647. [PubMed: 9485414]

33. Grabarse W, Mahlert F, Duin EC, Goubeaud M, Shima S, Thauer RK, Lamzin V, Ermler U. On the mechanism of biological methane formation: structural evidence for conformational changes in methyl-coenzyme M reductase upon substrate binding. J Mol Biol. 2001; 309:315-330. [PubMed: 11491299]

34. Grabarse W, Mahlert F, Shima S, Thauer RK, Ermler U. Comparison of three methyl-coenzyme M reductases from phylogenetically distant organisms: unusual amino acid modification, conservation and adaptation. J Mol Biol. 2000; 303:329-344. [PubMed: 11023796]

35. Horng YC, Becker DF, Ragsdale SW. Mechanistic studies of methane biogenesis by methylcoenzyme M reductase: evidence that coenzyme B participates in cleaving the $\mathrm{C}-\mathrm{S}$ bond of methyl-coenzyme M. Biochemistry. 2001; 40:12875-12885. [PubMed: 11669624] 
36. Berkessel A. Methyl-Coenzyme-M Reductase - Model Studies on Pentadentate Nickel-Complexes and a Hypothetical Mechanism. Bioorg Chem. 1991; 19:101-115.

37. Jaun B. Coenzyme-F430 from Methanogenic Bacteria - Oxidation of F430 Pentamethyl Ester to the Ni(Iii) Form. Helvetica Chimica Acta. 1990; 73:2209-2217.

38. Signor L, Knuppe C, Hug R, Schweizer B, Pfaltz A, Jaun B. Methane formation by reaction of a methyl thioether with a photo-excited nickel thiolate - A process mimicking methanogenesis in archaea. Chemistry-a European Journal. 2000; 6:3508-3516.

39. Chen SL, Pelmenschikov V, Blomberg MR, Siegbahn PE. Is there a Ni-methyl intermediate in the mechanism of methyl-coenzyme M reductase? J Am Chem Soc. 2009; 131:9912-9913. [PubMed: 19569621]

40. Pelmenschikov V, Blomberg MRA, Siegbahn PEM, Crabtree RH. A mechanism from quantum chemical studies for methane formation in methanogenesis. J Am Chem Soc. 2002; 124:4039_ 4049. [PubMed: 11942842]

41. Pelmenschikov V, Siegbahn PE. Catalysis by methyl-coenzyme M reductase: a theoretical study for heterodisulfide product formation. J Biol Inorg Chem. 2003; 8:653-662. [PubMed: 12728361]

42. Duin EC, McKee ML. A new mechanism for methane production from methyl-coenzyme M reductase as derived from density functional calculations. J Phys Chem. 2008; B 112:2466-2482.

43. Bobik TA, Wolfe RS. Physiological importance of the heterodisulfide of coenzyme M and 7mercaptoheptanoylthreonine phosphate in the reduction of carbon dioxide to methane in Methanobacterium. Proc Natl Acad Sci U S A. 1988; 85:60-63. [PubMed: 3124103]

44. Goenrich M, Duin EC, Mahlert F, Thauer RK. Temperature dependence of methyl-coenzyme M reductase activity and of the formation of the methyl-coenzyme $M$ reductase red2 state induced by coenzyme B. J Biol Inorg Chem. 2005; 10:333-342. [PubMed: 15846525]

45. Kunz RC, Dey M, Ragsdale SW. Characterization of the Thioether Product Formed from the Thiolytic Cleavage of the Alkyl-Nickel Bond in Methyl-Coenzyme M Reductase. Biochemistry. 2008; 47:2661-2667. [PubMed: 18220418]

46. Noll KM, Donnelly MI, Wolfe RS. Synthesis of 7-mercaptoheptanoylthreonine phosphate and its activity in the methylcoenzyme M methylreductase system. J Biol Chem. 1987; 262:513-515. [PubMed: 3100513]

47. Olson KD, McMahon CW, Wolfe RS. Photoactivation of the 2-(methylthio)ethanesulfonic acid reductase from Methanobacterium. Proc Natl Acad Sci U S A. 1991; 88:4099-4103. [PubMed: 1903534]

48. Zehnder AJ, Wuhrmann K. Titanium (III) citrate as a nontoxic oxidation-reduction buffering system for the culture of obligate anaerobes. Science. 1976; 194:1165-1166. [PubMed: 793008]

49. Gunsalus RP, Romesser JA, Wolfe RS. Preparation of coenzyme M analogues and their activity in the methyl coenzyme $\mathrm{M}$ reductase system of Methanobacterium thermoautotrophicum. Biochemistry. 1978; 17:2374-2377. [PubMed: 98178]

50. Otwinowski Z, Minor W. Processing of X-ray Diffraction Data Collected in Oscillation Mode. Methods in Enzymology: Macromolecular Crystallography, part A. 1997; 276:307-326.

51. The CCP4 suite: programs for protein crystallography. Acta Crystallogr D Biol Crystallogr. 1994; 50:760-763. [PubMed: 15299374]

52. Emsley P, Cowtan K. Coot: model-building tools for molecular graphics. Acta Crystallogr D Biol Crystallogr. 2004; 60:2126-2132. [PubMed: 15572765]

53. Ebner S, Jaun B, Goenrich M, Thauer RK, Harmer J. Binding of coenzyme B induces a major conformational change in the active site of methyl-coenzyme M reductase. J Am Chem Soc. 2010; 132:567-575. [PubMed: 20014831]

54. Goenrich M, Mahlert F, Duin EC, Bauer C, Jaun B, Thauer RK. Probing the reactivity of Ni in the active site of methyl-coenzyme M reductase with substrate analogues. J Biol Inorg Chem. 2004; 9:691-705. [PubMed: 15365904] 


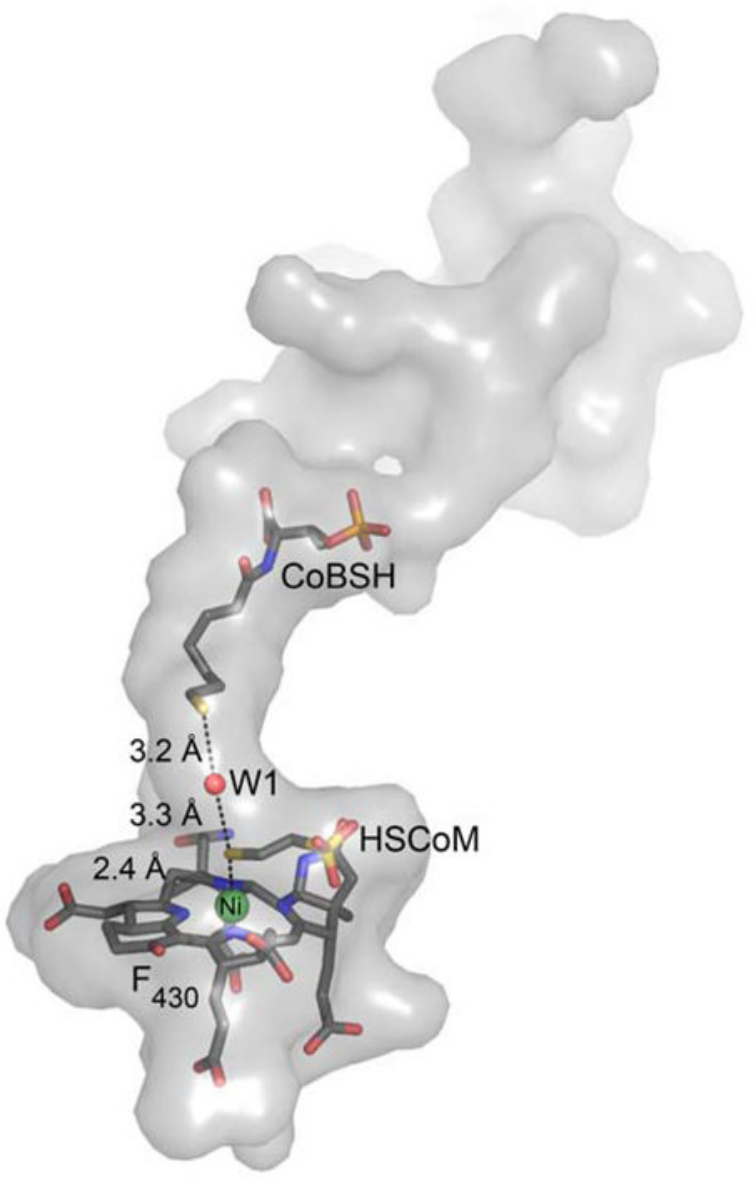

Figure 1.

The active site and substrate channel in the $\mathrm{MCR}_{\mathrm{Ox} 1 \text {-silent }}$ crystal structure (PDB code 1hbn) (9). Coenzyme $\mathrm{F}_{430}$, CoBSH and HSCoM are drawn as stick colored by atom (carbon: dark grey). The nickel is displayed as a green sphere, water as a red sphere. Interactions are drawn as dashed lines, and the corresponding distance is indicted in Angstroms ( $)$. The path of the substrate channel was defined in the absence of $\mathrm{F}_{430}, \mathrm{CoBSH}, \mathrm{HSCoM}$ and water, with the surface closest to the viewer cut away. The figure was generated using PyMOL (http://www.pymol.org). 


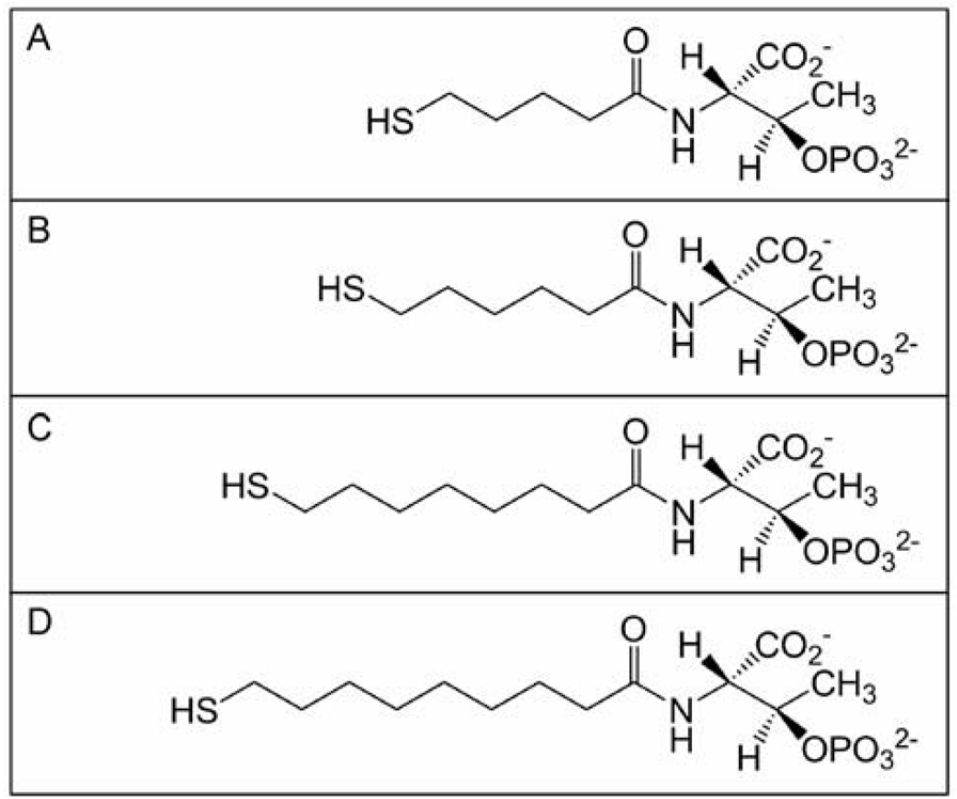

Figure 2.

Drawing of CoBSH analogues; (A) $N$-5-mercaptopentanoylthreonine phosphate $\left(\mathrm{CoB}_{5} \mathrm{SH}\right)$; (B) $N$-6-mercaptohexanoylthreonine phosphate $\left(\mathrm{CoB}_{6} \mathrm{SH}\right)$; (C) $N$-8mercaptooctanoylthreonine phosphate $\left(\mathrm{CoB}_{8} \mathrm{SH}\right)$; (D) $N$-9-mercaptononanoylthreonine phosphate $\left(\mathrm{CoB}_{9} \mathrm{SH}\right)$. 


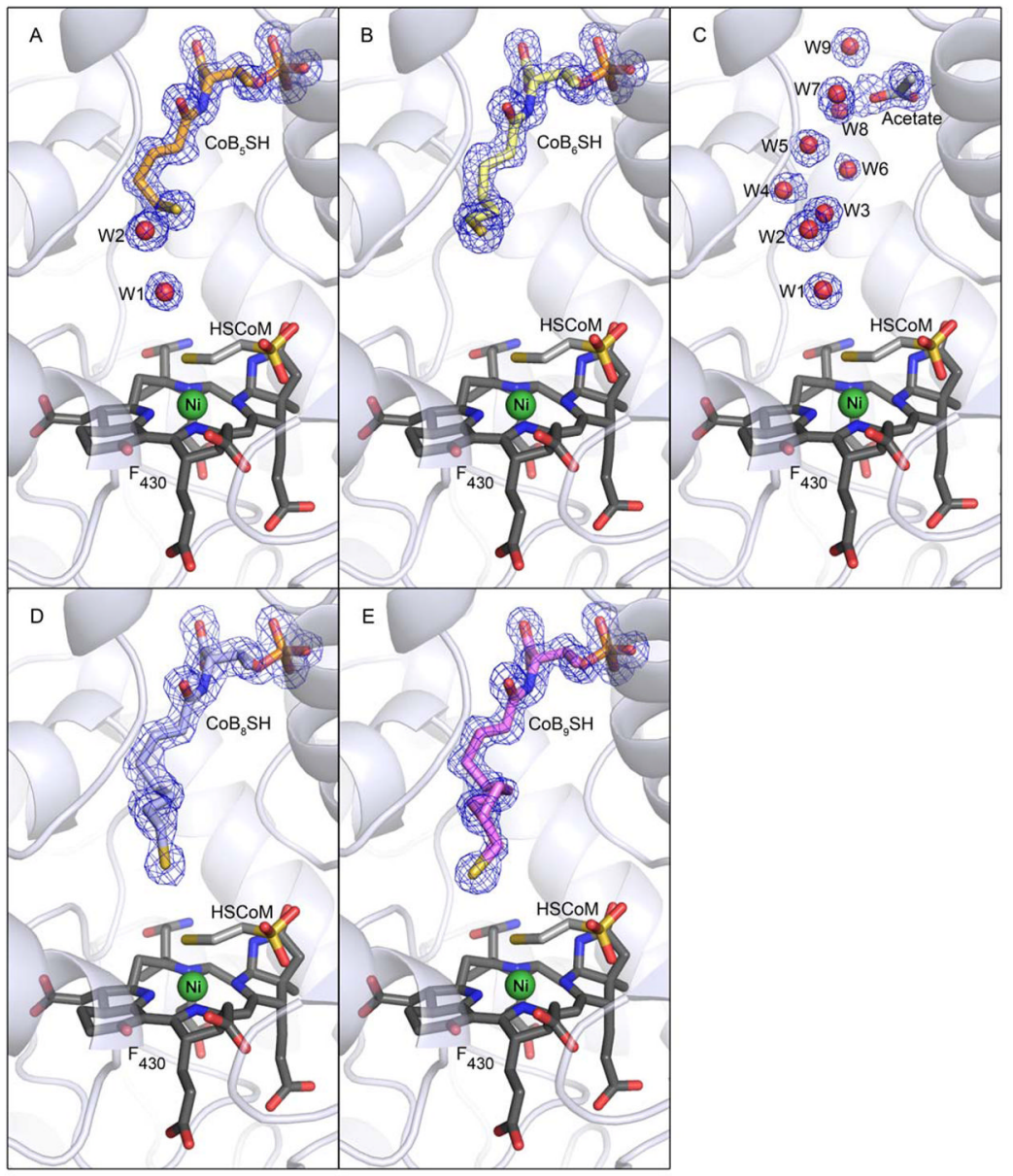

Figure 3.

The active sites and substrate channels of the MCR crystal structures.; (A) $\mathrm{MCR}_{\mathrm{CoB} 5 \mathrm{SH}}$; (B) $\mathrm{MCR}_{\mathrm{CoB} 6 \mathrm{SH}}$; (C) $\mathrm{MCR}_{\mathrm{HSCoM}}$; (D) $\mathrm{MCR}_{\mathrm{CoB} 8 \mathrm{SH}}$; (E) $\mathrm{MCR}_{\mathrm{CoB} 9 \mathrm{SH}}$. $2 \mathrm{Fo}-\mathrm{Fc}$ electron density map around the $\mathrm{CoB}_{X} \mathrm{SH}$ analogues, waters in the CoBSH binding part of the channel and the acetate ion (contoured at $1 \sigma$ ) is shown as a blue mesh. The protein is drawn as cartoon. $\mathrm{CoB}_{X} \mathrm{SH}$ and acetate are drawn as stick and colored by atom (carbon: $\mathrm{CoB}_{5} \mathrm{SH}$ orange; $\mathrm{CoB}_{6} \mathrm{SH}$ pale yellow; $\mathrm{CoB}_{8} \mathrm{SH}$ light blue; $\mathrm{CoB}_{9} \mathrm{SH}$ magenta; acetate white). Coenzyme $\mathrm{F}_{430}$ and $\mathrm{HSCoM}$ are drawn as stick colored by atom (carbon: $\mathrm{F}_{430}$ dark grey; HSCoM medium grey). The nickel is displayed as a green sphere, and waters as red spheres. The figure was generated using PyMOL (http://www.pymol.org/). 

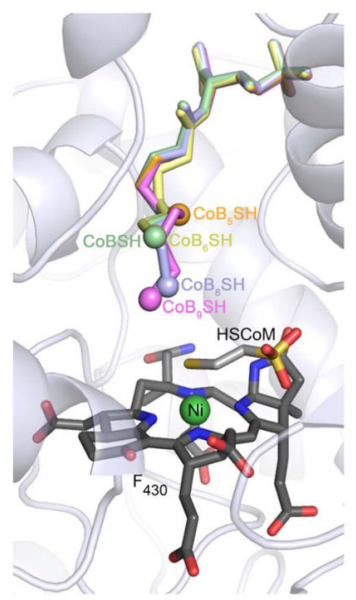

Figure 4.

Overlay of CoBSH (from PDB code $1 \mathrm{hbn}$ ) and the different $\mathrm{CoBSH}$ analogues. $\mathrm{CoB}_{X} \mathrm{SH}$ are drawn as stick with the thiol represented by a sphere, and colored $\mathrm{CoB}_{5} \mathrm{SH}$ orange; $\mathrm{CoB}_{6} \mathrm{SH}$ pale yellow; $\mathrm{CoBSH}$ light green; $\mathrm{CoB}_{8} \mathrm{SH}$ light blue; $\mathrm{CoB}_{9} \mathrm{SH}$ magenta. The protein is drawn as cartoon. Coenzyme $\mathrm{F}_{430}$ and $\mathrm{HSCoM}$ are drawn as stick colored by atom (carbon: $\mathrm{F}_{430}$ dark grey; HSCoM medium grey). The nickel is displayed as a green sphere. The figure was generated using PyMOL (http://www.pymol.org/). 


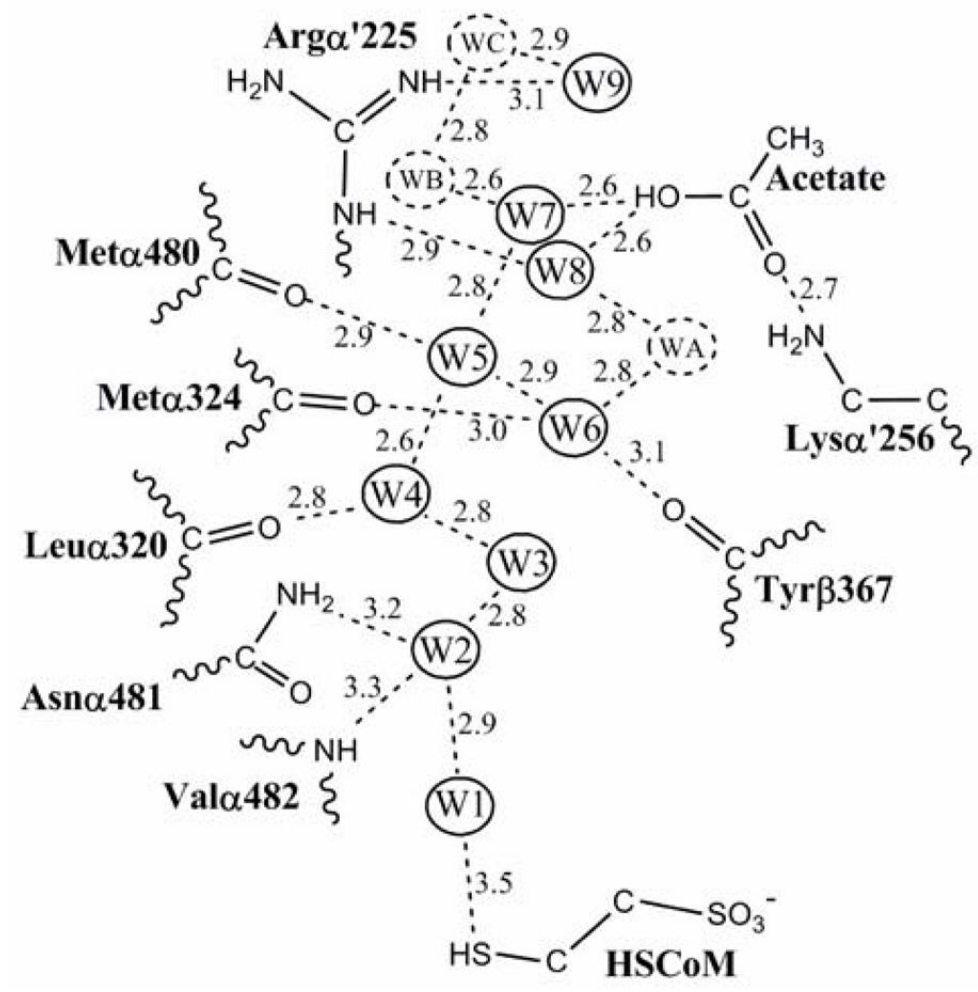

Figure 5.

Hydrogen bonding diagram for the water structure modeled in $\mathrm{MCR}_{\mathrm{HSCoM}}$. The water molecules are named as in Figure 3C (W1-W9); WA, WB and WC are water molecules that are present in all structures (i.e. in concert with the substrate $\mathrm{CoBSH}$ and the CoBSH analogues). Interactions between surrounding residues and the water molecules are drawn as dashed lines, and the corresponding distance is indicated in Angstroms ( $\mathrm{A})$. 


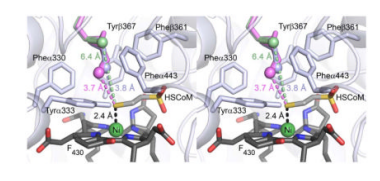

\section{Figure 6.}

Stereo image of the annulus of aromatic amino acids distal of coenzyme $F_{430}$. The protein is drawn as cartoon with the side-chains of the aromatic residues drawn as white stick.

$\mathrm{CoBSH}$, (from PDB code $1 \mathrm{hbn}(9)$ ), $\mathrm{CoB}_{8} \mathrm{SH}$ and $\mathrm{CoB}_{9} \mathrm{SH}$ are drawn as stick with the thiols represented by spheres, and colored $\mathrm{CoBSH}$ light green; $\mathrm{CoB}_{8} \mathrm{SH}$ light blue; $\mathrm{CoB}_{9} \mathrm{SH}$ magenta. Coenzyme $\mathrm{F}_{430}$ and HSCoM are drawn as stick colored by atom (carbon: $\mathrm{F}_{430}$ dark grey; HSCoM medium grey). The nickel is displayed as a green sphere. The figure was generated using PyMOL (http://www.pymol.org/). 
<smiles>CSCCS(=O)(=O)O[Na]</smiles><smiles>C[C@H](O[R6](=O)(=O)O[Na])[C@H](NC(=O)CCCCCCSSCC[SH](=O)[O-])C(=O)[O-]</smiles>

Scheme 1.

Reaction catalyzed by methyl-coenzyme M reductase 
A

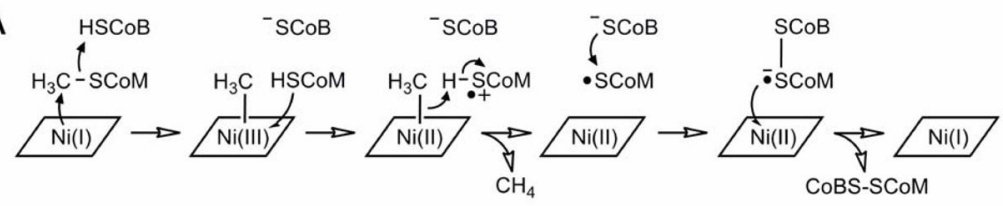

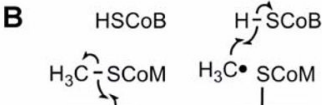

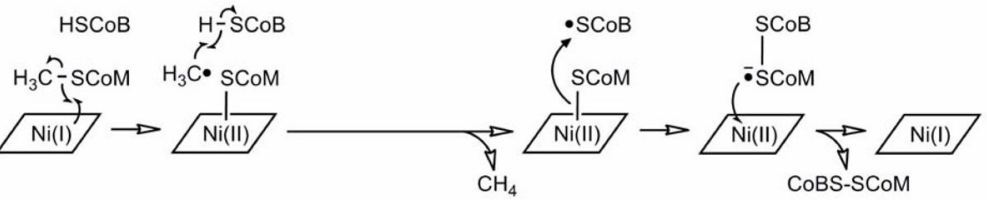

Scheme 2.

Two of the proposed catalytic mechanisms for methyl-coenzyme M reductase; (A) mechanism I; (B) mechanism II. 


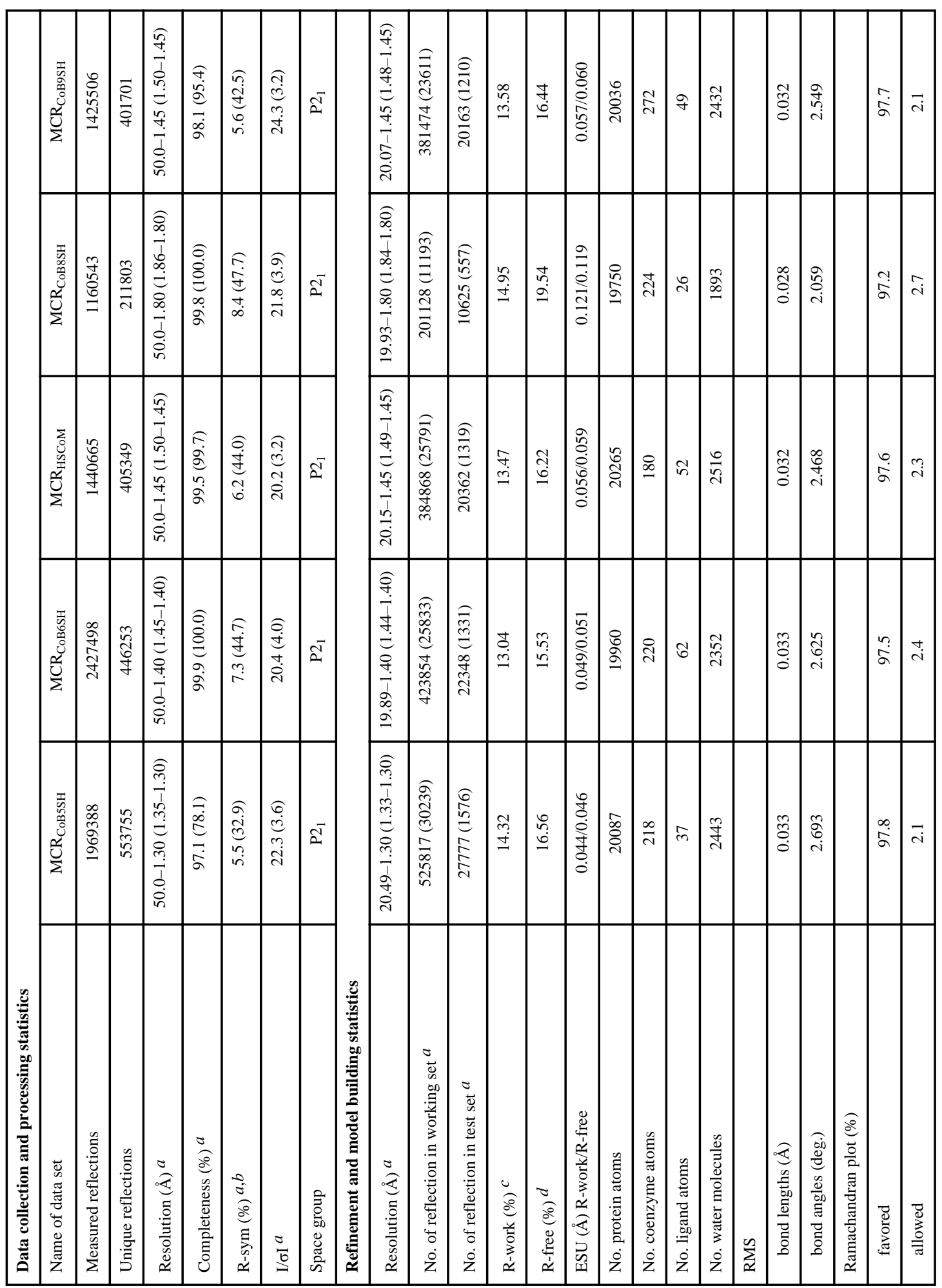




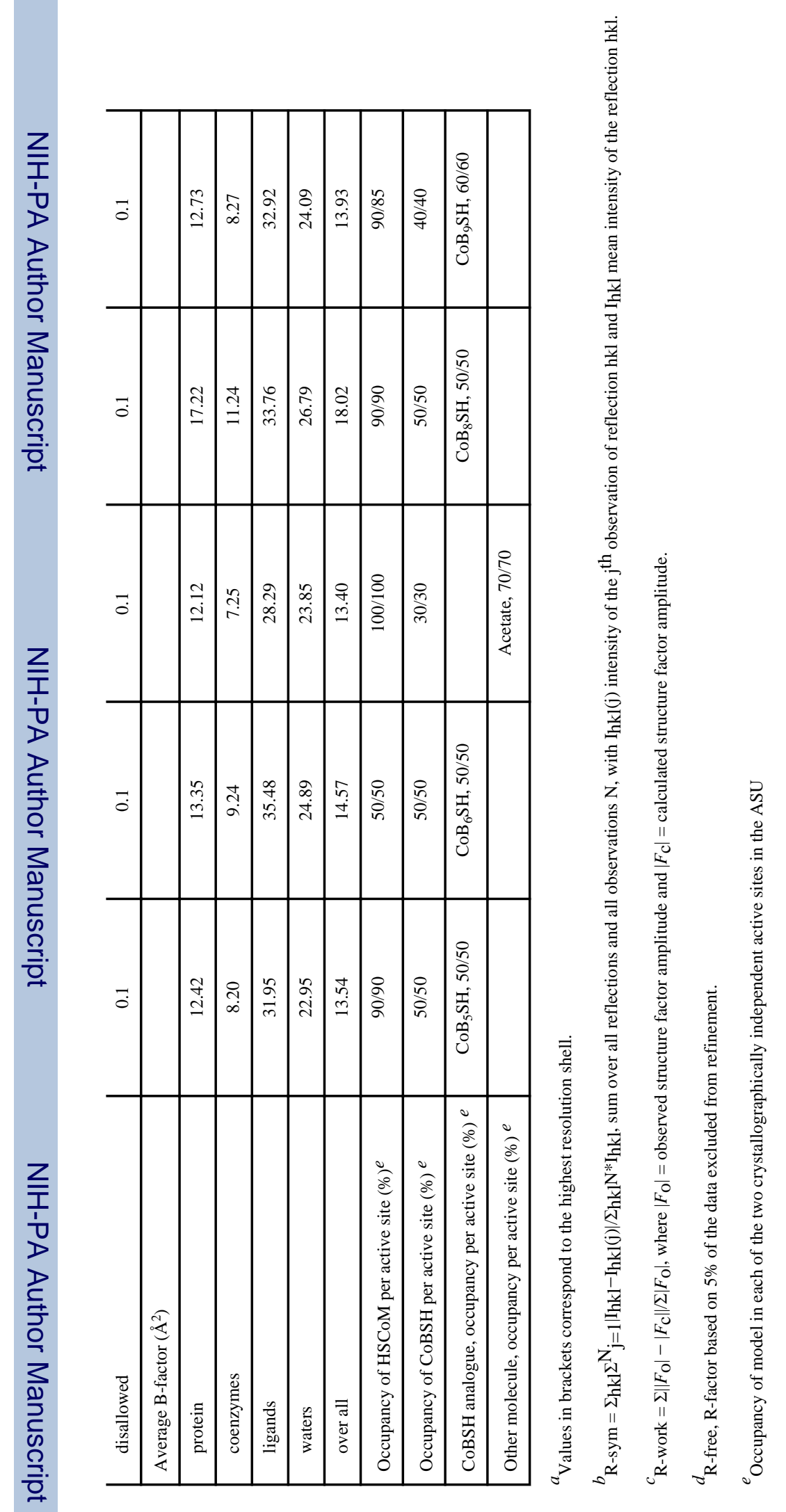


Table 2

Distances from analogue thiols.

\begin{tabular}{|l|c|c|}
\hline & $\mathbf{C o B}_{X} \mathbf{S}-\mathbf{S C o M}$ distance $(\mathbf{A})$ & $\mathbf{C o B}_{X} \mathbf{S}$ - Ni distance (̊̊) \\
\hline $\mathrm{CoB}_{5} \mathrm{SH}$ & $7.11 / 7.11^{a}$ & $9.30 / 9.30$ \\
\hline $\mathrm{CoB}_{6} \mathrm{SH}$ & $6.26 / 6.26$ & $8.70 / 8.70$ \\
\hline $\mathrm{CoB}_{7} \mathrm{SH}$ (substrate) $^{b}$ & $6.37 / 6.39$ & $8.73 / 8.77$ \\
\hline $\mathrm{CoB}_{8} \mathrm{SH}$ & $3.75 / 3.78$ & $6.16 / 6.17$ \\
\hline $\mathrm{CoB}_{9} \mathrm{SH}$ & $3.71 / 3.68$ & $5.96 / 5.91$ \\
\hline
\end{tabular}

${ }^{a}$ Distances in the two crystallographically independent active sites in the ASU

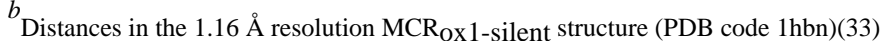

